\title{
Nanostructured Cellulose-Gellan-Xyloglucan- Lysozyme Dressing Seeded with Mesenchymal Stem Cells for Deep Second-Degree Burn Treatment
}

This article was published in the following Dove Press journal: International Journal of Nanomedicine

\section{Carolina Maria Costa de Oliveira Souza, iD ${ }^{\prime}$ Clayton Fernandes de Souza, (iD ${ }^{2,3}$ Bassam Felipe Mogharbel, (ID)' Ana Carolina Irioda, (iD)' Celia Regina Cavichiolo Franco, (iD) ${ }^{4}$ Maria Rita Sierakowski, (iD ${ }^{3}$ Katherine Athayde Teixeira de Carvalho, (iD) ${ }^{\prime}$ \\ 'Stem Cell Research Laboratory, Cell Therapy and Biotechnology in Regenerative Medicine Department, Pequeno Príncipe Faculties and the Pelé Pequeno Príncipe Research Institute, Curitiba, Paraná, Brazil; ${ }^{2}$ Chemistry \\ Undergraduate Program, School of Education and Humanities, Pontifícia Universidade Católica Do Paraná, Curitiba, Paraná, Brazil; ${ }^{3}$ BioPol, Chemistry Department, Federal University of Paraná, Curitiba, Paraná, Brazil; ${ }^{4}$ Molecular Biology Department, Federal University of Paraná, Curitiba, Paraná, Brazil}

\section{Video abstract}

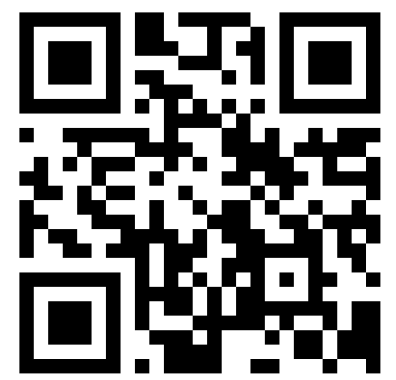

Point your smartphone at the code above. If you have a $Q R$ code reader, the video abstract will appear. Or use: https://youtu.be/_blsOH5XFlc

Correspondence: Katherine Athayde Teixeira de Carvalho

Stem Cell Research Laboratory, Cell Therapy and Biotechnology in Regenerative Medicine

Department, Pequeno Príncipe Faculties and the

Pelé Pequeno Príncipe Research Institute, 1632

Avenida Silva Jardim, Box 80.240-020, Curitiba,

Paraná, Brazil

Tel +55 4I-33I0-1034

Email katherinecarv@gmail.com
Purpose: In deep burns, wound contraction and hypertrophic scar formation can generate functional derangement and debilitation of the affected part. In order to improve the quality of healing in deep second-degree burns, we developed a new treatment in a preclinical model using nanostructured membranes seeded with mesenchymal stem cells (MSCs).

Methods: Membranes were obtained by reconstitution of bacterial cellulose (reconstituted membrane $[\mathrm{RM}]$ ) and produced by a dry-cast process, then RM was incorporated with $10 \%$ tamarind xyloglucan plus gellan gum 1:1 and 10\% lysozyme (RMGT-LZ) and with 10\% gellan gum and 10\% lysozyme (RMG-LZ). Membrane hydrophobic/hydrophilic characteristics were investigated by static/dynamic contact-angle measurements. They were cultivated with MSCs, and cell adhesion, proliferation, and migration capacity was analyzed with MTT assays. Morphological and topographic characteristics were analyzed by scanning electron microscopy. MSC patterns in flow cytometry and differentiation into adipocytes and osteocytes were checked. In vivo assays used RMG-LZ and RMGT-LZ (with and without MSCs) in Rattus norvegicus rats submitted to burn protocol, and histological sections and collagen deposits were analyzed and immunocytochemistry assay performed.

Results: In vitro results demonstrated carboxyl and amine groups made the membranes moderately hydrophobic and xyloglucan inclusion decreased wettability, favoring MSC adhesion, proliferation, and differentiation. In vivo, we obtained $40 \%$ and $60 \%$ reduction in acute/chronic inflammatory infiltrates, 96\% decrease in injury area, increased vascular proliferation and collagen deposition, and complete epithelialization after 30 days. MSCs were detected in burned tissue, confirming they had homed and proliferated in vivo.

Conclusion: Nanostructured cellulose-gellan-xyloglucan-lysozyme dressings, especially when seeded with MSCs, improved deep second-degree burn regeneration.

Keywords: skin, cell-based therapy, transplantation, hydrocolloid dressing

\section{Introduction}

According to the World Health Organization, a burn is an injury to the skin or other organic tissue primarily caused by heat or due to radiation, radioactivity, electricity, friction, or contact with chemical products. ${ }^{1}$ Burns are classified according to the extent of the burned surface and the depth reached: first (superficial), second (partial thickness, it can be superficial or deep), and third (full thickness) degrees. ${ }^{2}$

The healing of burns follows the same process as wound healing, consisting of highly integrated and overlapping stages: inflammation, cell recruitment, matrix deposition, epithelialization, and tissue remodeling. ${ }^{3}$ 
In deep burn injuries, treatments aim to promote a microenvironment conducive to healing, protecting the area against microbial contamination. ${ }^{4}$ Many dressings are available for burn treatment, from gauze coverings, therapeutic topical agents, antiseptic solutions, polyurethane biofilms, hydrocolloids, and hydrogels to the most complex, known as bioactive dressings. ${ }^{5}$

Cellulose dressings are biologically inert and do not cause hypersensitivity, and were popularized in the 1980s, initially indicated as a synthetic graft and temporary substitute for the skin. ${ }^{6}$ This cellulose is obtained from Gluconacetobacter xylinu secretions, ${ }^{7}$ and has a stable, gelatinous, three-dimensional mesh structure, great elasticity, and mechanical strength, ${ }^{8}$ and its micro- and nanofibers create a functional surface with high absorptive capacity. ${ }^{9}$

In addition to cellulose, new dressings have been developed using natural polymers, such as alginate, chitosan, arabic gum, gellan gum, and cellulose derivatives (methylcellulose, carboxymethylcellulose, and others), due to their high biocompatibility, biodegradability, and physiological activity. ${ }^{10,11}$

Nanostructured membranes obtained from polymers can be an alternative in improving the healing process of burns, due to their large ratio of surface to volume, the formation of a mesh permeated by pores of varying sizes, and a three-dimensional structure that allows application as scaffolding. ${ }^{12}$

Incorporation of bioactive additives on polymer matrix can modify the surface, resulting in changes in roughness, hydrophilicity, cell affinity, and consequently adhesion and proliferation of cells in the substrate. ${ }^{13,14}$ Blending different polymers allows the improvement of biocomposites to generate charged surfaces with variable functional characteristics. ${ }^{15}$ Different hydrogels have been used for wound healing, due to their hygroscopic nature and soft tissue-like mechanical performance, ${ }^{16}$ among them gellan gum and tamarind xyloglucan.

Gellan gum is a biocompatible, atoxic, thermoresponsive, ductile exopolysaccharide produced by Sphingomonas elodea, and its versatility allows its use in different applications of regenerative medicine and tissue engineering. ${ }^{17}$ However, simple gellan gels have unfavorable properties, such as hardness, brittleness, low mechanical strength, and high critical gelationtemperature, which can be reversed by introducing another polymer as a blended or chemically bonded component. ${ }^{18,19}$ As such, cellulose blended with gellan seems to be an efficient system for burn healing.
Tamarind xyloglucan is a branched polysaccharide isolated from seeds of Tamarindus indica, ${ }^{20}$ usually used as a binder, gelling agent, emulsifier, release modifier in pharmaceutical formulations, and matrix former. It is water-soluble, biodegradable, and biocompatible. ${ }^{21}$ These characteristics aid the development of a microenvironment conducive to skin recovery.

The use of mesenchymal stem cells (MSCs) in burns has become effective, resulting in faster tissue recovery, promoting reduction of wound contraction, and avoiding formation of hypertrophic scars. ${ }^{22,23}$ These findings are attributed to the differentiation capacity of MSCs, repopulating injured tissue where they are transplanted and stimulating a cascade of paracrine effects. ${ }^{24}$ MSCs can be isolated from various tissue types, such as bone marrow, adipose tissue, dental pulp, skin, umbilical cord blood, and amniotic membrane. ${ }^{25,26}$ They are undifferentiated pluripotent cells that proliferate while maintaining their undifferentiated state, possess self-renewal capacity, can be differentiated in multilines, and have immunomodulatory activity. ${ }^{27,28}$

The incorporation of MSCs into biomaterials that behave as cellular scaffolds allows a higher rate of cell adhesion and proliferation, due to their biocompatibility and biomimetic texture, ${ }^{29}$ therefore, these bioengineered systems are promising candidates as an efficient treatment in burn injuries.

The aim of this study was to compare the efficiency of burn regeneration promoted by micro- and nanostructured cellulose-gellan-xyloglucan-lysozyme dressings, seeded or not with MSCs, analyzing acute and chronic inflammation, vascular proliferation, epithelialization, collagen deposition, and reduction of wound area in a rat model.

\section{Methods}

Due to the use of Wistar rats (Rattus norvegicus) to perform MSC isolation and burn procedures, this study was submitted to the Ethics Committee on the Use of Animals of the Pequeno Príncipe Hospital Complex and was approved (015-2012). All animal procedures followed the guidelines of the Brazilian Ethics Committee on the Use of Animal Subjects in accordance with the Guidelines for the Care and Use of Laboratory Animals published by the US National Institutes of Health. ${ }^{36}$

\section{Mesenchymal Stem Cell Isolation and Expansion}

MSCs were isolated from rat adipose tissue. After rat death, epididymal adipose tissue was removed, washed, 
digested with PBS (Sigma-Aldrich, St Louis, MO, USA), and supplemented with 2\% FBS (Gibco, Grand Island, NY, USA) and $0.2 \%$ collagenase IA (SigmaAldrich) at $37^{\circ} \mathrm{C}$ for 45 minutes. Cell suspensions were centrifuged at $600 \mathrm{~g}$ for 5 minutes. The supernatant was discarded and the cell pellet resuspended in DMEM/F12 medium (Sigma-Aldrich) supplemented with $10 \%$ FBS, $1 \%$ penicillin $100 \mathrm{IU} / \mathrm{mL}$, and streptomycin $0.1 \mathrm{mg} / \mathrm{mL}$ (Sigma-Aldrich), then seeded in culture bottles $\left(10^{5}\right.$ cells $\left./ \mathrm{cm}^{2}\right)$ and incubated at $37^{\circ} \mathrm{C}, 5 \%$ $\mathrm{CO}_{2}$, until $90 \%$ confluence. ${ }^{30}$ After this, cells were trypsinized and seeded on membranes. Samples of these cells were used to perform MSC characterization.

\section{Mesenchymal Stem Cell Characterization}

Flow-cytometry analysis and adipogenic and osteogenic differentiation were performed to validate the MSCs. Cells were incubated with specific monoclonal antibodies for 15 minutes at room temperature in a dark room: ${ }^{31}$ control (just cells), isotype control phycoerythrin (PE), isotype control FITC, control PERCP-Cy5, control PECy7, CD34 PE, CD45 PERCP-Cy5, CD73 FITC, and CD90 PE-Cy7. All antibodies were used at the concentrations recommended by the manufacturer. The cell-membrane markers used were CD34 PE, CD45 (PerCP-Cy5-5), CD73 (FITC), and CD90 (PE-CY7; BD Bioscience, Franklin Lakes, NJ, USA). FITC mouse $\operatorname{IgG}_{1} \kappa$, PE mouse $\operatorname{IgG}_{2 \mathrm{a}} \kappa$, PE-Cy7 mouse $\operatorname{IgG}_{1} \kappa$, PERCP mouse $\mathrm{IgG}_{1} \kappa$ (BD Bioscience) were the isotype negative controls. The samples were read by the flow-cytometry apparatus FACS Canto II (BD Biosciences), with 20,000 events for each specimen.

Isolated cells were submitted to adipogenic and osteogenic induced media using DMEM/F12 medium (Sigma-Aldrich), 10\% FBS (Gibco), 1\% penicillin plus streptomycin (Sigma-Aldrich), supplemented with 0.01 $\mathrm{Mm}$ 1.25-dihydroxyvitamin $\mathrm{D}_{3}, 50 \mu \mathrm{M}$ ascorbate-2phosphate, and $10 \mathrm{mM} \quad \beta$-glycerophosphate for adipogenic differentiation (14 days) and $0.5 \mathrm{mM}$ isobutyl-methylxanthine, $1 \mu \mathrm{M}$ dexamethasone, $10 \mu \mathrm{M}$ insulin, and $200 \mu \mathrm{M}$ indomethacin (Sigma-Aldrich) for osteogenic differentiation (35 days). ${ }^{32,33}$ At the end of the differentiation period, samples were stained for adipocyte and osteocyte visualization.

Differentiation procedures were performed on RMGTLZ membranes seeded with MSCs to verify the differentiation capacity on the membrane.

\section{Nanostructured Bacterial Cellulose- Based Membranes}

Four cellulose membranes were used in this study, a commercial one, produced and donated by Membracel (Curitiba, Paraná, Brazil), the other three developed and provided by the BioPol Lab, Department of Chemistry, Federal University of Paraná. Membracel dressing (MC) is made of bacterial cellulose, naturally produced, and consists in a resistant microstructured mesh. BioPol Lab dressings are fresh bacterial cellulose membranes that have been defibrillated mechanically to obtain a pulp used to form reconstituted membrane (RM). The nanomembranes produced were just the RM, RM with $10 \%$ tamarind xyloglucan plus gellan gum 1:1 and 10\% lysozyme (RMGT-LZ) and RM with $10 \%$ gellan gum and $10 \%$ lysozyme (RMG-LZ). ${ }^{15}$ Reconstitution of the membranes was performed by a dry-cast process.

\section{Static and Hysteretic Contact-Angle Measurements on Membranes}

Contact angles were determined using a contact-angle goniometer (OCA 15 Plus;DataPhysics Instruments, Filderstadt, Germany). Measurements were performed at $20^{\circ} \mathrm{C}$ using a $500 \mu \mathrm{L}$ syringe and a needle of internal and external diameters of 1.37 and $1.65 \mathrm{~mm}$, respectively, and a length of $38.1 \mathrm{~mm}$. The hydrophobic/hydrophilic character of the dressing membranes in relation to liquid of the MSC culture was investigated using the sessile drop method and DMEM/ F12 medium containing 10\% FBS as test liquid. The hysteresis of the contact angle was determined by recording the advancing (adv) and receding (rec) angles at the moment just before the droplet rolled off and calculating the difference in the contact angles $\left(\Delta \theta_{\text {hyst }}=\theta_{a d v}-\cos \theta_{\text {rec }}\right)$. All measurements were performed in triplicate.

\section{Mesenchymal Stem-Cell Adhesion and Proliferation Assays}

All dressing membranes were cut using a sterile punch, generating circular fragments measuring about $2 \mathrm{~cm}$ in diameter. Each fragment was placed in a well of a 24well plate. MSCs were seeded on the membranes at $10^{3}$ cells $/ \mathrm{cm}^{2}$ with $1 \mathrm{~mL}$ of DMEM/F12 medium, 10\% FBS, $1 \%$ penicillin $100 \mathrm{IU} / \mathrm{mL}$, and streptomycin $0.1 \mathrm{mg} / \mathrm{mL}$, and incubated at $37^{\circ} \mathrm{C}, 5 \% \mathrm{CO}_{2}$, for 2 hours and for 7 days. The procedure was performed in triplicate.

To check MSC adhesion, the first reading was performed after 2 hours of incubation. To compare 
proliferation capacity, the other reading was performed after 7 days of incubation. Both assays used MTT.

For the analysis, membranes were removed from the culture well and transferred to another plate without medium. Then, $500 \mu \mathrm{L}$ MTT solution $(0.5 \mathrm{mg}$ MTT $/ \mathrm{mL}$ culture medium) was added and the plates incubated at $37^{\circ} \mathrm{C}$ for 3 hours. The MTT solution was withdrawn from the plates and $200 \mu \mathrm{L}$ dimethyl sulfoxide (Sigma-Aldrich) was added to dissolve the salts formed by the MTT. The dimethyl sulfoxide was transferred to a 96-well plate and absorbance reading by spectrophotometry performed using an EL800 ELISA reader (BioTek Instruments, Winooski, VT, USA) at awavelength of $595 \mathrm{~nm} .{ }^{34}$

The same process was carried out in the original culture wells, so cells that had migrated from the membrane to the bottom of the well were counted. A standard curve was constructed with known amounts of cells, ranging from $10^{3}$ to $10^{5}$. Both blank and standard cells underwent the same procedure.

\section{Scanning Electron Microscopy}

RMG-LZ, RMGT-LZ, and MC membranes were cultivated for 7 days with MSCs. Membranes were washed with $0.1 \mathrm{Mol} / \mathrm{L}$ sodium cacodylate buffer, $\mathrm{pH} 7.4$ at $4^{\circ} \mathrm{C}$. MSCs were fixed in Karnovski solution (2\% glutaraldehyde, $4 \%$ paraformaldehyde, $1 \mathrm{mMol} / \mathrm{L}$ calcium chloride in $0.1 \mathrm{Mol} / \mathrm{L}$ cacodylate buffer, $\mathrm{pH}$ 7.2-7.4) for 1 hour and washed three times in $0.1 \mathrm{Mol} / \mathrm{L}$ sodium cacodylate buffer, $\mathrm{pH}$ 7.4. Membranes were dehydrated with crescent ethanol concentrations $(30 \%, 50 \%, 70 \%, 90 \%$, and $100 \%$ twice) for 10 minutes at each concentration, then critical point and gold coating were obtained. ${ }^{35}$ Images were obtained with scanning electron microscopy (SEM; JSM-6360LV; Jeol, Tokyo, Japan) for analysis of integration between cells and membranes and cell morphology on membrane surfaces.

\section{Burn- and Membrane-Treatment Protocols in Preclinical Model}

Seventy male Wistar $R$. norvegicus rats weighing $300 \mathrm{~g}$ were used to analyze cellulose membrane treatments (with and without MSCs), and initially all animals were submitted to the burn protocol.

In order to obtain second-degree burns, rats were anesthetized with ketamine $(10 \mathrm{mg} / \mathrm{kg})$ and xylazine $(50$ $\mathrm{mg} / \mathrm{kg}$ ) intraperitoneally, had their dorsum shaved, and the skin was then exposed to an iron bar (heated at $100^{\circ} \mathrm{C}$ ) for
30 seconds. ${ }^{34}$ Each animal received two burns. After 48 hours, animals were anesthetized and had lesions debrided for treatment application.

Rats were divided into four groups according to treatments:

control group - ten animals had both burns cleaned with sterile saline $0.9 \%$ and covered with gauze fixed with microporous tape around their abdomen;

RMGT-LZ group - 20 animals had one of their burns covered with RMGT-LZ membrane seeded with MSCs and on the other burn was placed RMGT-LZ membrane without MSCs;

RMG-LZ group - 20 animals had one of their burns covered with RMG-LZ membrane seeded with MSCs and on the other burn was placed RMG-LZ membrane without MSCs;

MC group - 20 animals had one of their burns covered with MC membrane seeded with MSCs and on the other burn was placed MC membrane without MSCs.

Half the animals were killed 5 days after treatment and the rest after 30 days. Wound measurements were recorded by scanned manual planimetry, and histological sections were taken for analysis of fragments.

\section{Histopathological Analysis}

The histological sections were stained with HE and ten fields at $400 \times$ magnification from each slide visualized under optical microscopy and scored. Qualitative analysis was performed identifying inflammatory cells (acute and chronic inflammatory infiltrates), vessels (vascular proliferation), and epithelialization area, allowing the classification of acute inflammation, chronic inflammation, epithelialization, and fibrosis at 5 and 30 days.

Collagen deposition in the injury area was quantified by Sirius red staining of 5- and 30-day histological sections. To perform the analysis, ten images of each sample were captured and processed using Image-Pro Plus 4.5 (Media Cybernetics, Rockville, MD, USA), calculating the percentage of area occupied by red and yellow (collagen I) and green (collagen III) fibers and scoring scar maturation. ${ }^{37}$

\section{Immunocytochemistry Assays}

A sample of MSCs used for seeding RMGT-LZ was labeled with BrdU (BD Bioscience) and DAPI (BD Bioscience) to label cell nuclei, both in accordance with the manufacturer. The burn protocol and treatment were applied to one rat to verify cell migration and proliferation in vivo. After 15 days, 
the histological fragment of the treated wound was revealed by FITC-anti-BrdU (Sigma-Aldrich).

\section{Statistical Analysis}

$\mathrm{R}$ open-source software (R Foundation for Statistical Computing, Vienna, Austria) was used for statistical analyses and ANOVA to determine whether any differences between means were statistically significant $(p \leq 0.05)$. Tukey's test was applied to evaluate absolute differences between mean values of the samples in relation to controls (MC and RM) in vitro experiments. Scanned manual planimetry was calculated using AutoCAD (Autodesk, San Rafael, CA, USA) and analyzed by ANOVA and Tukey's test. Histopathological evaluations and percentages of collagen deposition were analyzed by Fisher's test.

\section{Results}

\section{Flow-Cytometry Analysis and Differentiation Assays}

Flow-cytometry analysis demonstrated the isolated cells were $\mathrm{CD} 34^{-}, \mathrm{CD}_{4} 5^{-}, \mathrm{CD}_{3} 3^{+}$, and $\mathrm{CD}^{+} 0^{+}$(Figure 1).
They were able to differentiate in adipogenic (Figure 2A) and osteogenic cells (Figure 2B) in the well and on RMGT-LZ (Figure 2D and E). Controlled differentiation assays were done (Figure $2 \mathrm{C}$ and $\mathrm{F}$ ).

\section{Contact-Angle Measurements on} Membranes

Contact-angle analysis was performed to evaluate the effect of the additives on cellulose-based membranes. The first effect was observed in the static contact angle), showing an increase after inclusion of gellan gum, tamarind xyloglucan, and lysozyme. Tukey's test showed a significant difference between modified membranes with the additives in relation to MC and RM $(p<0.05)$, indicating an increase in hydrophobicity on surfaces of the RMG-LZ and RMGT-LZ (Figure 3A).

The second effect, related to roughness and heterogeneity in the membrane surfaces, was evaluated using advancing and receding contact-angle measurements (hysteretic analysis). The results are shown in Figure 3B, and significant difference between RMG-LZ and RMGT-LZ

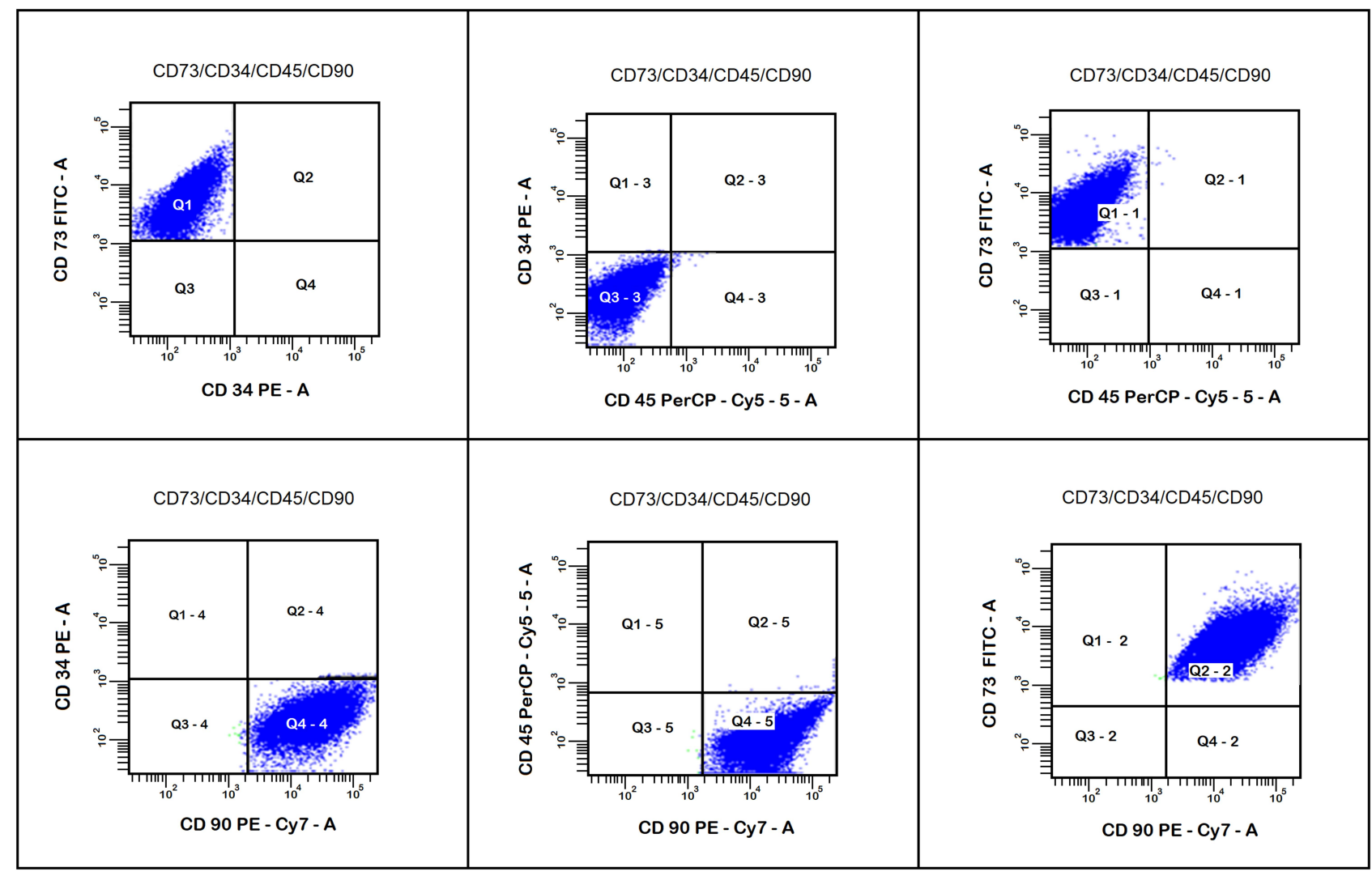

Figure I Biparametric graphs divided into four quadrants of results obtained by flow cytometry. Comparison between cell immunostainers is indicated in each graph. 

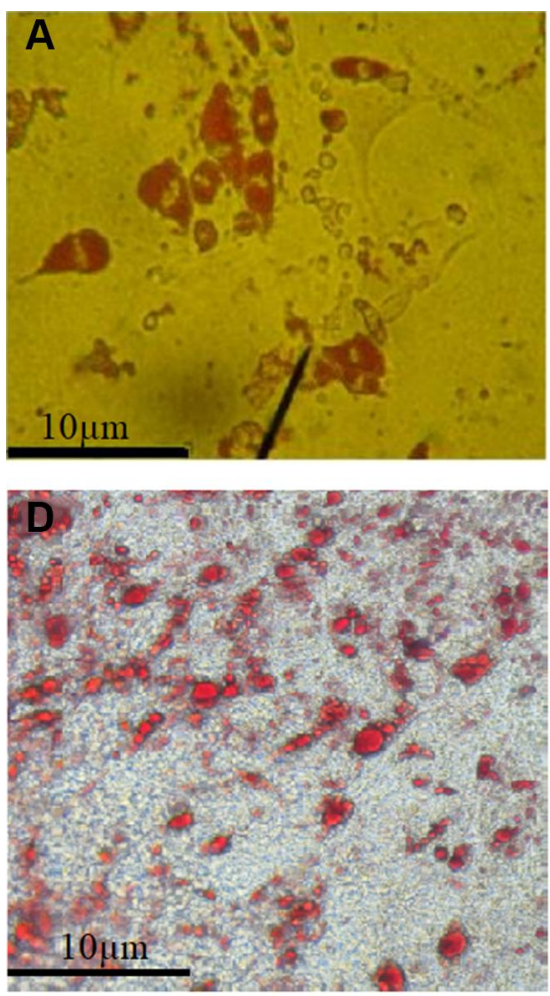
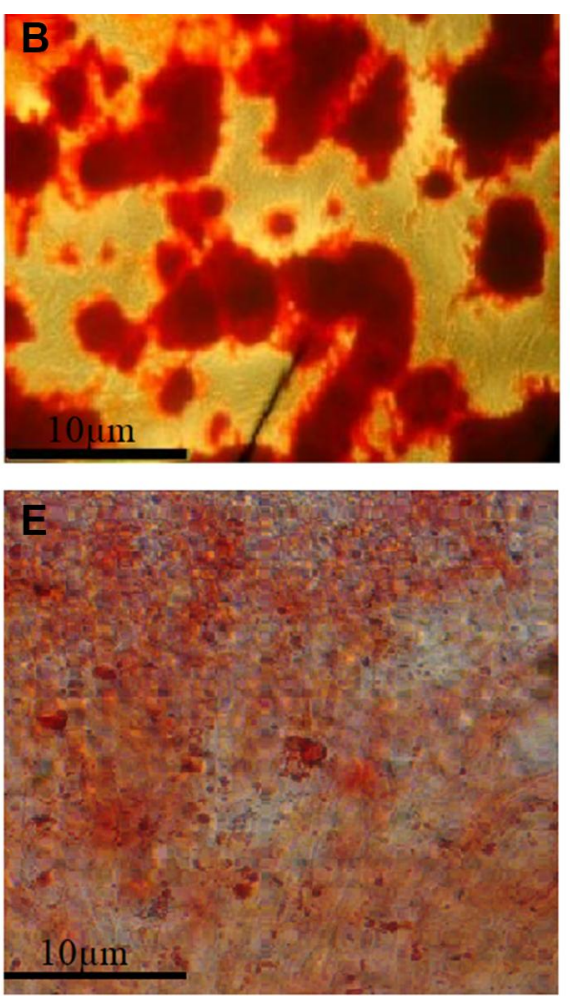
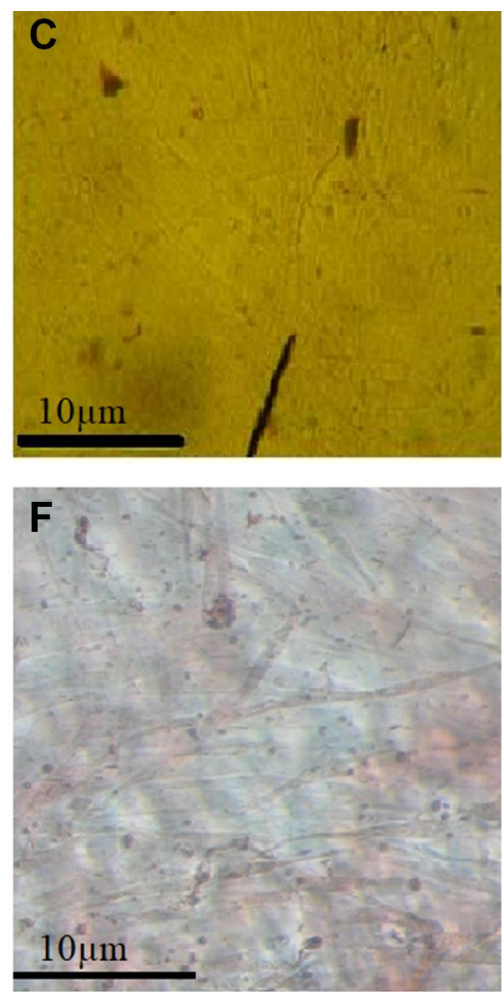

Figure 2 Microscopy of isolated MSCs in culture flasks, 100×. (A) MSCs differentiated in adipocytes; (B) MSCs differentiated in osteocytes; (C) MSCs in standard cultivation medium; (D) MSCs differentiated in adipocytes on RMGT-LZ; (E) MSCs differentiated in osteocytes on RMGT-LZ; (F) MSCs in standard cultivation medium on RMGT-LZ. Abbreviations: MSCs, mesenchymal stem cells; RMGT-LZ, reconstituted cellulose membrane with $10 \%$ tamarind xyloglucan plus gellan gum I:I and I0\% lysozyme.

A

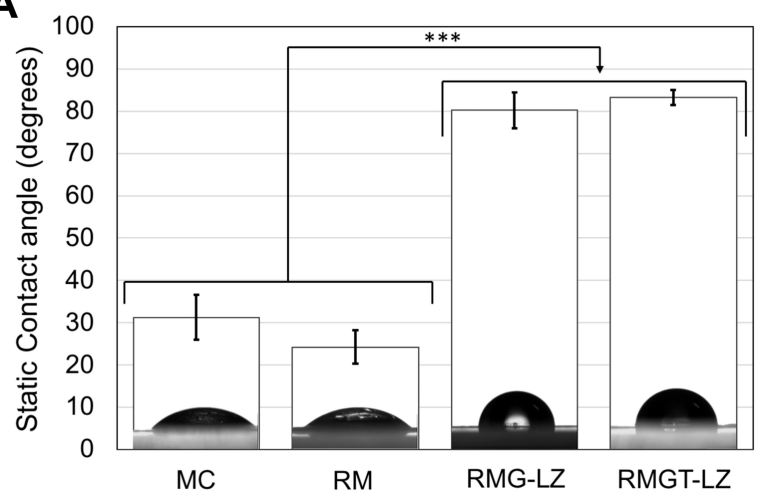

B

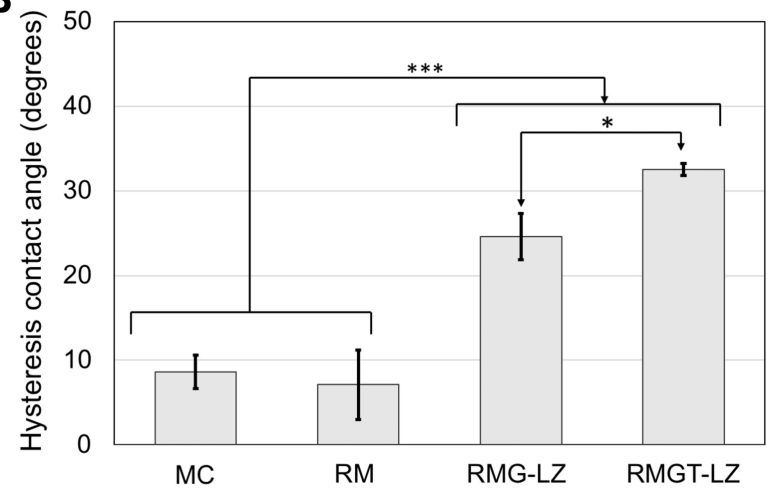

Figure 3 Static (A) and hysteretic (B) contact-angle results of DMEM solution on membranes $(* p \leq 0.05, * * * p \leq 0.001)$.

Abbreviations: MC, cellulose membrane; RM, reconstituted MC; RMG-LZ, RM with $10 \%$ gellan gum and $10 \%$ lysozyme; RMGT-LZ, RM with $10 \%$ tamarind xyloglucan plus gellan gum I:I and 10\% lysozyme.

in relation to MC and RM $(p<0.001)$ was observed. In addition, low statistical difference was observed between RMG-LZ and RMGT-LZ $(p<0.05)$.

The inclusion of tamarind xyloglucan decreased RMGT-LZ wettability more than RMG-LZ and RM wettability. These results demonstrated that the presence of hydrocolloids and protein changed the physical and chemical characteristics of the membrane surfaces, which can influence interactions between the adsorbent and the adsorbate, resulting in more spreading of DMEM and modulating adhesion and proliferation of the cells.

\section{Adhesion and Proliferation Assays}

The cell adhesion on membranes is presented in Figure 4A. Rates of cell adhesion remained between 5.8\% (MC) and 9\% (RMG-LZ). RMGT-LZ and RMG-LZ obtained significantly better results than $\mathrm{MC}(p<0.05$ and $p<0.01)$. 

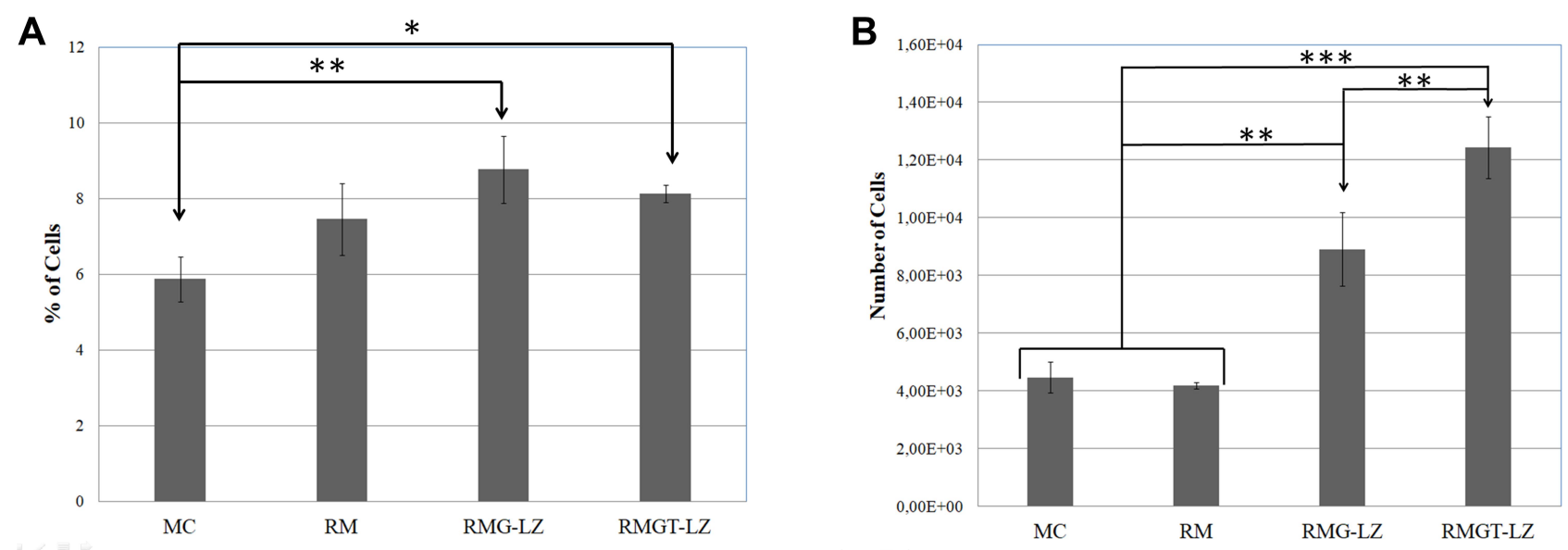

Figure 4 Results of adhesion (A) and proliferation (B) of mesenchymal stem cells seeded on membranes $(* p \leq 0.05, * * p \leq 0.0 \mathrm{I}, * * * p \leq 0.00 \mathrm{I})$.

Abbreviations: MC, cellulose membrane; RM, reconstituted MC; RMG-LZ, RM with $10 \%$ gellan gum and I0\% lysozyme; RMGT-LZ, RM with I0\% tamarind xyloglucan plus gellan gum I:I and 10\% lysozyme.

Proliferation rates corresponded to $4.5 \times 10^{3}$ cells for $\mathrm{MC}$, $4.2 \times 10^{3}$ cells for RM, $8.8 \times 10^{3}$ cells for RMG-LZ, and $12.4 \times 10^{3}$ cells for RMGT-LZ.There was a significant difference between RMG-LZ and RMGT-LZ $(p<0.05)$ and a strongly significantdifference comparing both of them to MC and $\mathrm{RM}(p<0.01$ and $p<0.001$, Figure 4B).

Cells were able to migrate from RMGT-LZ, RMG$\mathrm{LZ}$, and MC toward the bottom of the culture well and there was no significant difference among the rates ( $p>0.05)$ : 249 cells for RMGT-LZ, 237 cells for RMGLZ, and 242 cells for MC.

\section{Scanning Electron Microscopy Analysis}

SEM allowed morphological comparison of the entanglement of cellulose fibers with the interposition of lysozyme in RMG-LZ and RMGT-LZ structures. The cellulose fibers of $\mathrm{MC}$ were approximately $100 \mathrm{~nm}$ thick. In contrast, the cellulose fibers of RMGT-LZ and RMG-LZ were 10-50 nm thick. The interaction between cells and membranes showed how the cells expanded, maintaining the normal morphology compatible with MSC characteristics (Figure 5).

\section{Histopathological Analysis}

Acute-inflammation analysis at 5 days (Figure 6A) presented no significant difference between the groups, despite a variation in percentages: means of accentuated and moderate acute inflammatory infiltrates were equal for all groups. Even so, there was a tendency of difference between the RMGT-LZ with and without MSCs compared to the control group, pointing to greater efficiency in inflammatory response ( $70 \%$ of cases were accentuated).
Following the evolution of acute inflammation in 30 days (Figure 6B), RMGT-LZ groups with and without MSCs showed reduction in inflammatory infiltrates in 90\% samples from day 5. RMGT-LZ with MSCs showed acute inflammatory infiltrates discreet in 50\% and absent in $40 \%$ of samples $(p=0.02)$, and RMGT-LZ without MSCs reduced to discreet and absent in $80 \%$ and $10 \%$ of samples $(p=0.03)$. MC with cells also showed good resolution of the inflammatory process, in which $80 \%$ of samples evolved to discreet $(p=0.02)$. The control group continued to present acute inflammatory infiltrates in $30 \%$ of samples.

Chronic inflammatory infiltrate cells were observed from day 5 (Figure 6C). They were moderately present in $60 \%$ of MC with MSCs $(p=0.01$ ), and after 30 days $70 \%$ of samples had changed from moderate to discreet inflammatory infiltrates $(p=0.02)$ (Figure 6D). It is important to note that $70 \%$ and $60 \%$ of the RMGT-LZ groups with and without MSCs had no increase in inflammatory infiltrates in 30 days, remaining as discreet.

Vascular proliferation in 5 days (Figure 7A) presented a significant difference for RMG-LZ groups with and without MSCs $(p=0.03)$, showing its better performance in the initial days following the burn. At the end of 30 days (Figure 7B), the RMGT-LZ group presented complete epithelialization in $90 \%$ of its samples, a significant result $(p=0.02)$ compared to the control group. This showed the same pattern as in Figure 6A, indicating samples that presented accentuated acute inflammatory infiltrate cells at day 5 also obtained a better rate of epithelialization (by microscopic evaluation). 

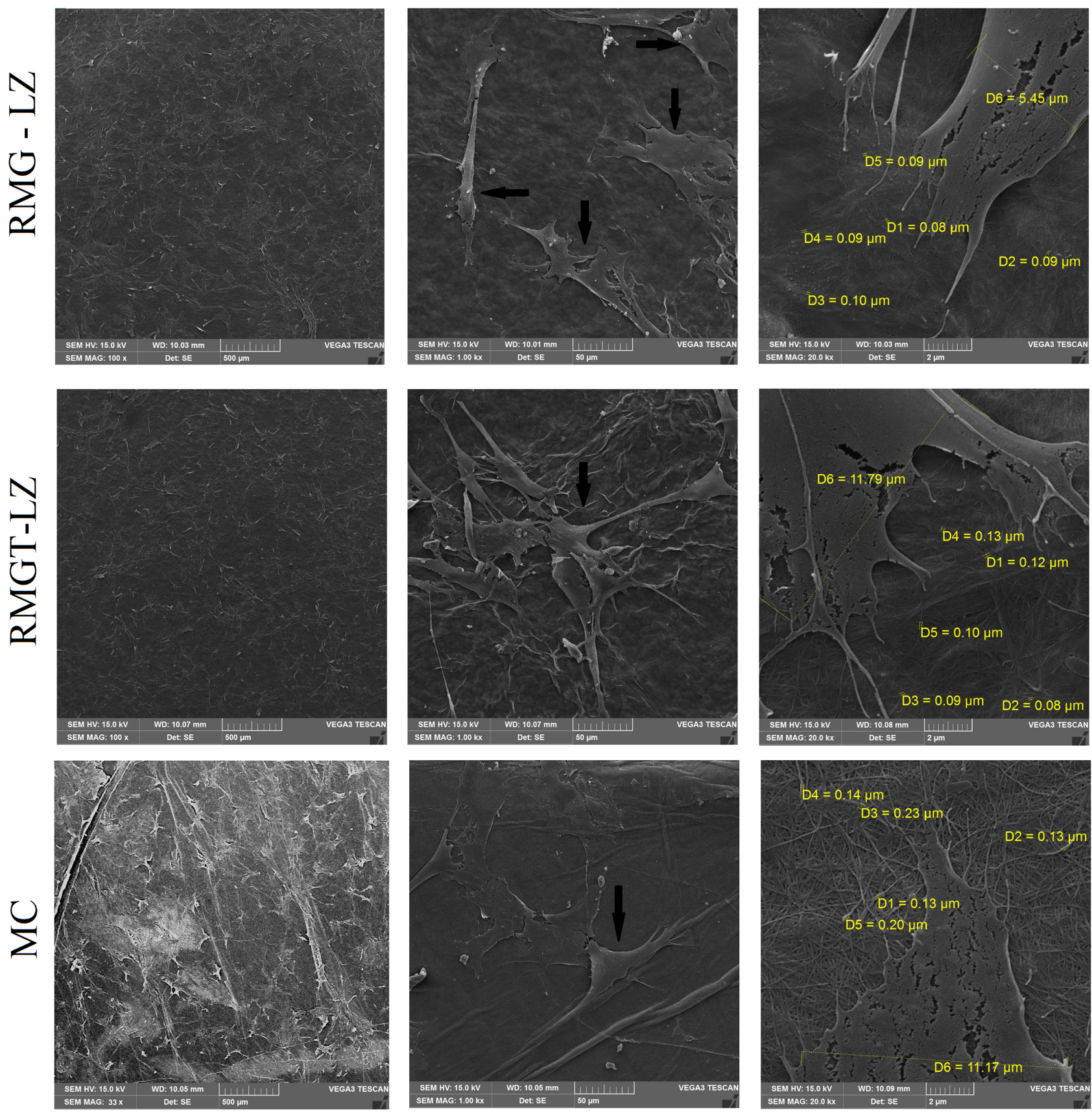

Figure 5 Scanning electron microscopy of membranes seeded with MSCs and comparison of MSC morphology on the membranes at different magnifications. In the images in the second column, the arrows point to the MSCs. In the images in the third column, the values of the width of some fibers are indicated, allowing the comparison of the mesh of each membrane and its possible relationship with cell interaction.

Abbreviations: DI-4, fiber width; D5, cellular width; MSCs, mesenchymal stem cells; MC, cellulose membrane; RM, reconstituted MC; RMG-LZ, RM with I0\% gellan gum and 10\% lysozyme; RMGT-LZ, RM with 10\% tamarind xyloglucan plus gellan gum I:I and 10\% lysozyme.

Digitalized manual planimetry result showed that the rate of reduction of the lesion area from day 5 to 30 was on average $97 \%$ for RMGT-LZ, RMG-LZ and MC groups seeded with MSCs, $94 \%$ for all groups without MSCs, and $88 \%$ for the control group.A significant difference occurred between groups seeded with MSCs and the control group $(p=0.02)$.
Macroscopic evolution can be observed in Figure 7C-F.

The evolution of the healing process of the burn is evident in histological sections in Figure 8A-N) comparing days 5 and 30 of all groups.

There was no significant difference between the deposition of type I and type III collagen at day 5 in the 
A

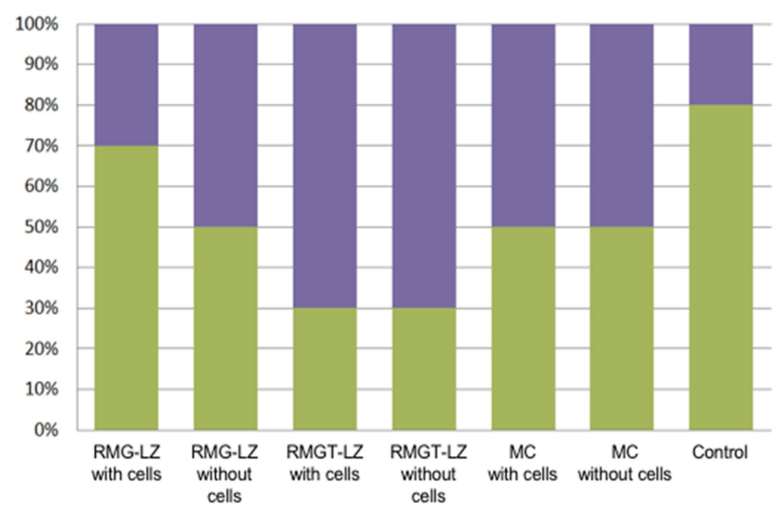

C

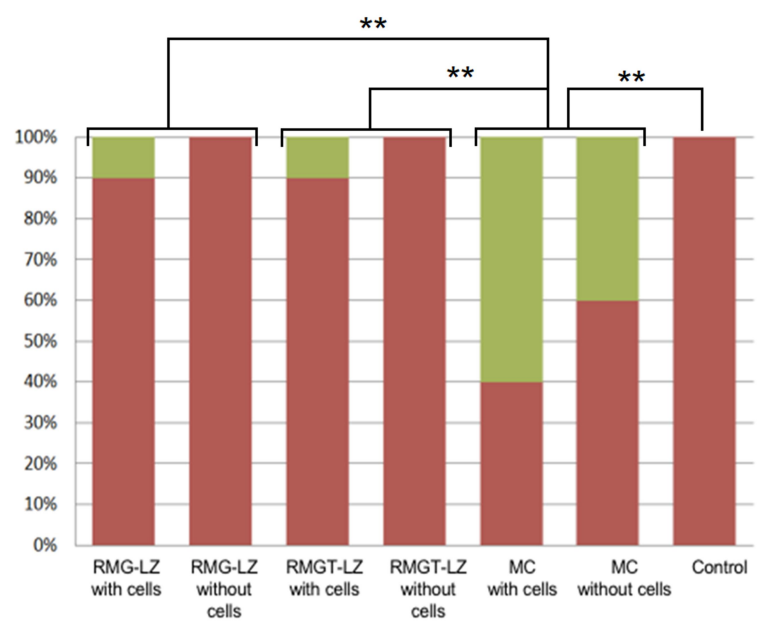

B

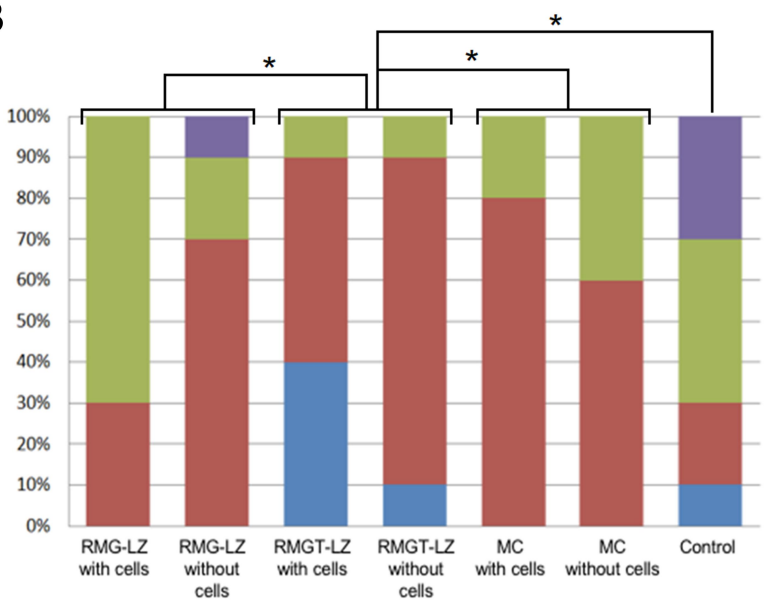

D

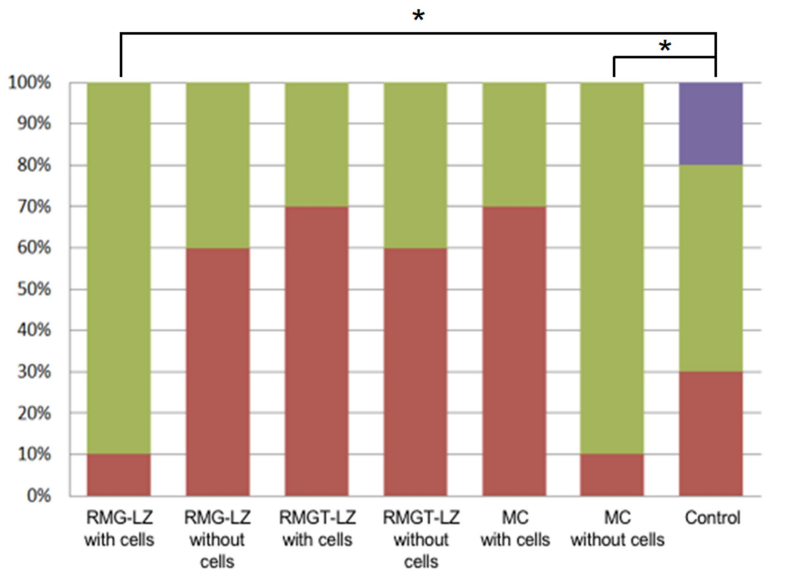

Accentuated $\square$ Moderate $\square$ Discreet $\square$ Absent

Figure 6 Acute inflammation analysis on days $5(\mathbf{A})$ and $30(\mathbf{B})$ and chronic inflammation analysis on days 5 (C) and 30 (D) $(* p \leq 0.05, * * p \leq 0.01)$.

Abbreviations: MC, cellulose membrane; RM, reconstituted MC; RMG-LZ, RM with $10 \%$ gellan gum and $10 \%$ lysozyme; RMGT-LZ, RM with I0\% tamarind xyloglucan plus gellan gum 1:I and 10\% lysozyme.

collagen area. However, at 30 days, all treatment groups showedequal type I collagen-deposition rates, significantly differing from the control group $(p=0.03)$, and the MC group seeded with MSCs obtained a higher rate of type I collagen deposition than the control group ( $p=0.03$; Table 1, Figure 9A-D).

\section{Immunocytochemistry Assays}

Cells incorporate BrdU when performing mitosis in the $\mathrm{S}$ phase of chromosome duplication and continue to express this compound, which integrates the cell's genetic material, because it is analogous to thymidine. After development, these cells appear with green marking. The joint blue marking corresponds to DAPI, which identifies cell nuclei. Immunocytochemistry showed that MSCs homed to inflamed tissue and proliferated in vivo (Figure 10), indicating that MSCs seeded on RMGT-LZ acted effectively in the healing process.

\section{Discussion}

In this study, an experimental preclinical model of burn injury was used to evaluate the influence of nanostructured cellulose-gellan-xyloglucan-lysozyme dressings seeded (or not) with MSCs on different parameters of tissue healing. The first step was to isolate and analyze the MSCs from adipose tissue. Results of immunophenotyping by flow cytometry added to the capacity of differentiation in 


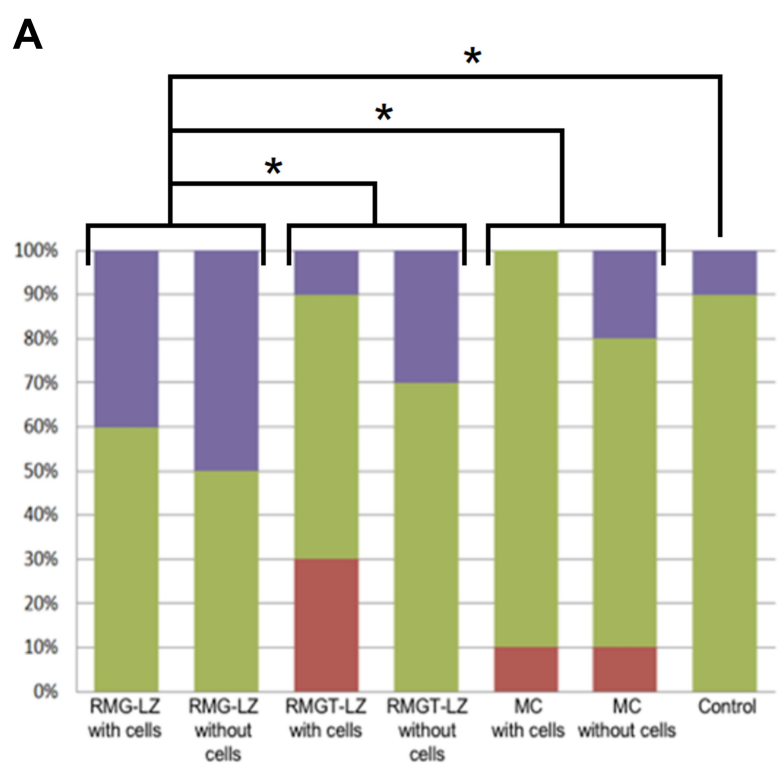

accentuated $\mathbf{n}$ Moderated $\mathbf{m}$ Discreet $\mathbf{m}$ Absent
B

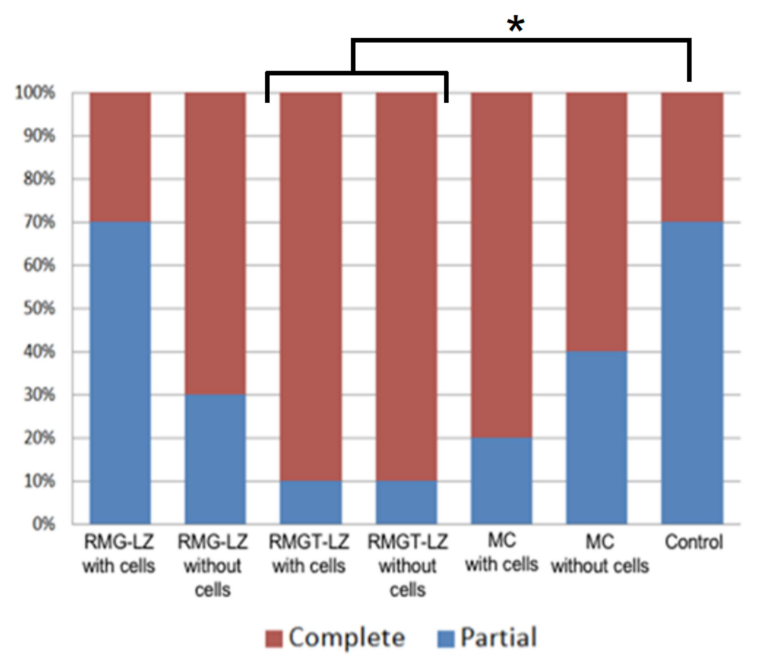

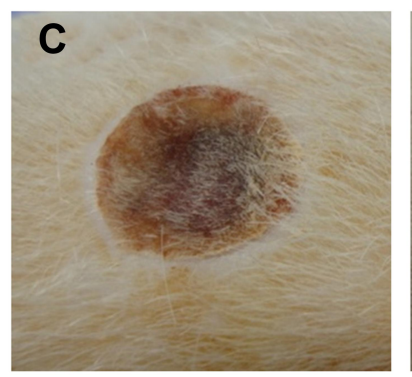
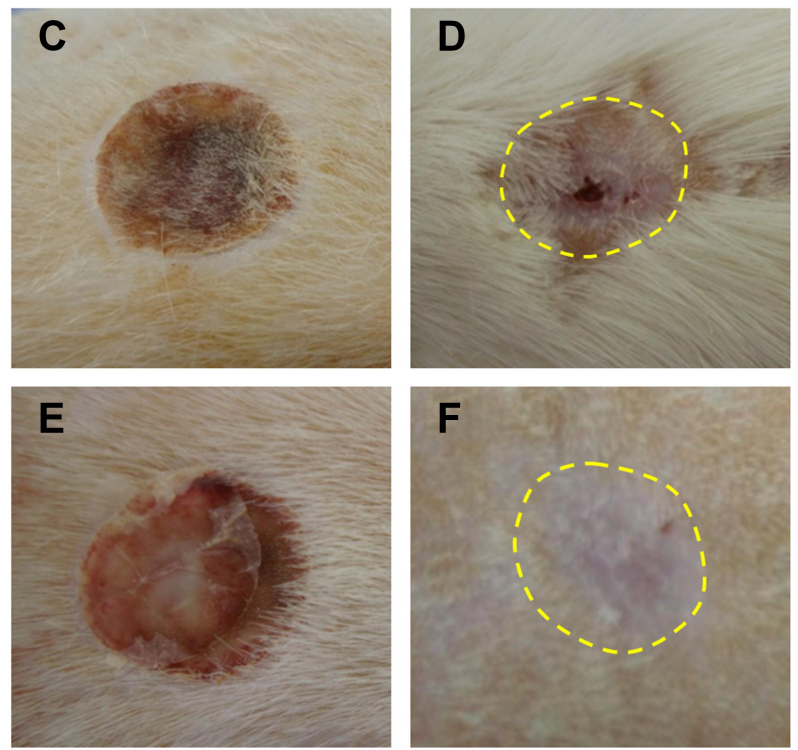

Figure 7 Vascular proliferation results on day $5(\mathbf{A})$ and epithelialization results on day $30(\mathbf{B})(* p \leq 0.05)$. Photographs comparing the healing obtained after debridement and treatment. Photos of the control group on days 5 (C) and 30 (D); other photo of RMGT-LZ seeded with MSCs on days 5 (E) and 30 (F). The dotted circle indicates the scar area.

Abbreviations: MSCs, mesenchymal stem cells; RMGT-LZ, reconstituted cellulose membrane with I0\% tamarind xyloglucan plus gellan gum I:I and I0\% lysozyme.

adipogenic and osteogenic lines confirmed that the isolated cells were adipose tissue-derived MSCs. ${ }^{38,39}$

Herein, the cellulose-based membranes functioned as scaffolds, were cytocompatible, and supported cellular adhesion, proliferation, and differentiation. RMG-LZ and RMGT-LZ showed reasonable cell adhesion and the best rate of cell proliferation in relation to MC. This can be explained by the presence of gellan gum and lysozyme in the carboxyl and amine groups. As previously observed, these functional groups can work as cell-recognition receptors, favoring cell adhesion and proliferation. ${ }^{40}$

In this way, membrane surfaces are favorable to good adhesion for MSCs, and this was observed on SEM with MSCs added to membrane surfaces showing typical morphology. The specific properties of each polymer can activate the secretion of cytokines and adhesive proteins, stimulating cell proliferation, ${ }^{41}$ so good adhesion can promote good proliferation, confirmed by the best 

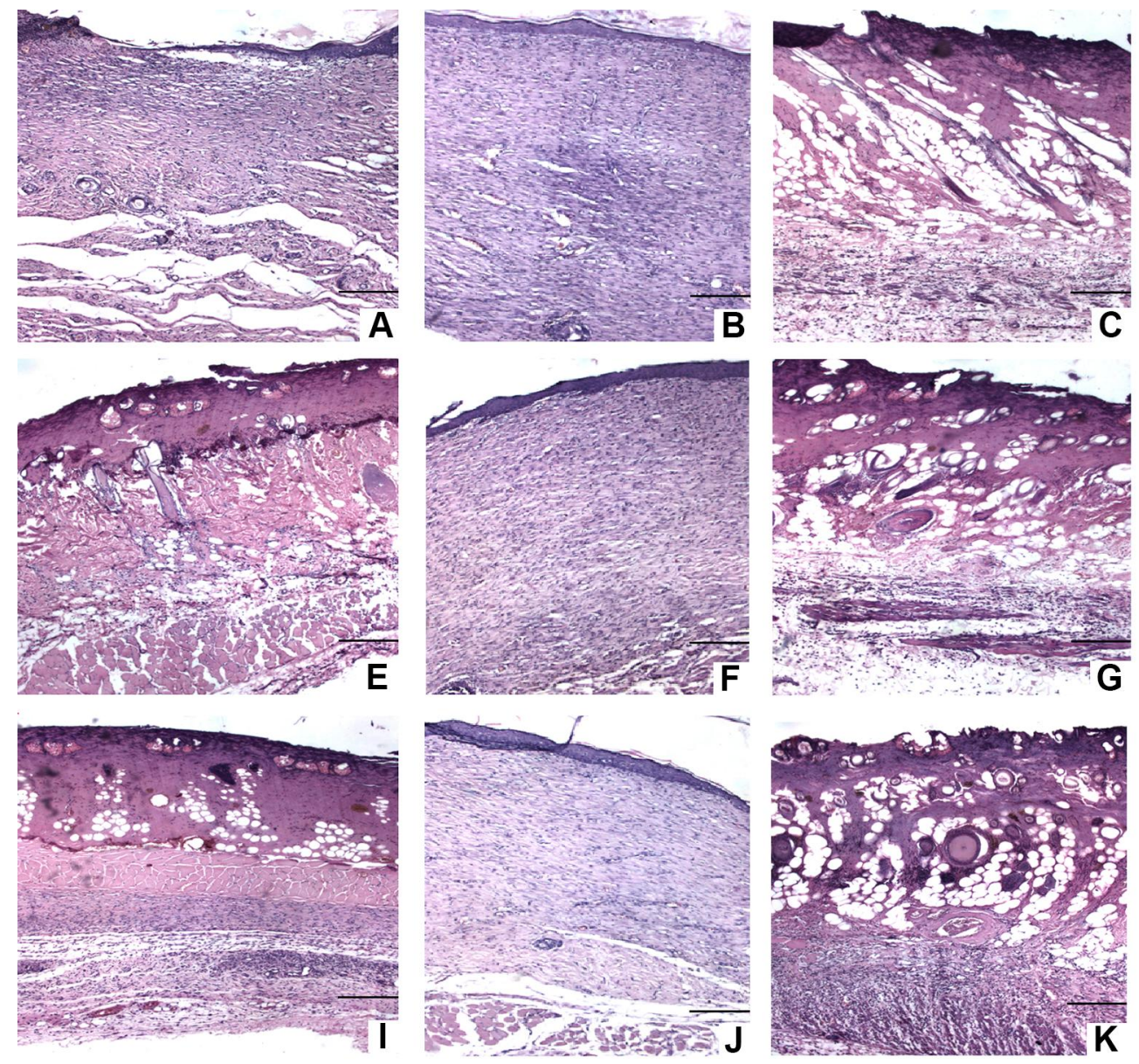
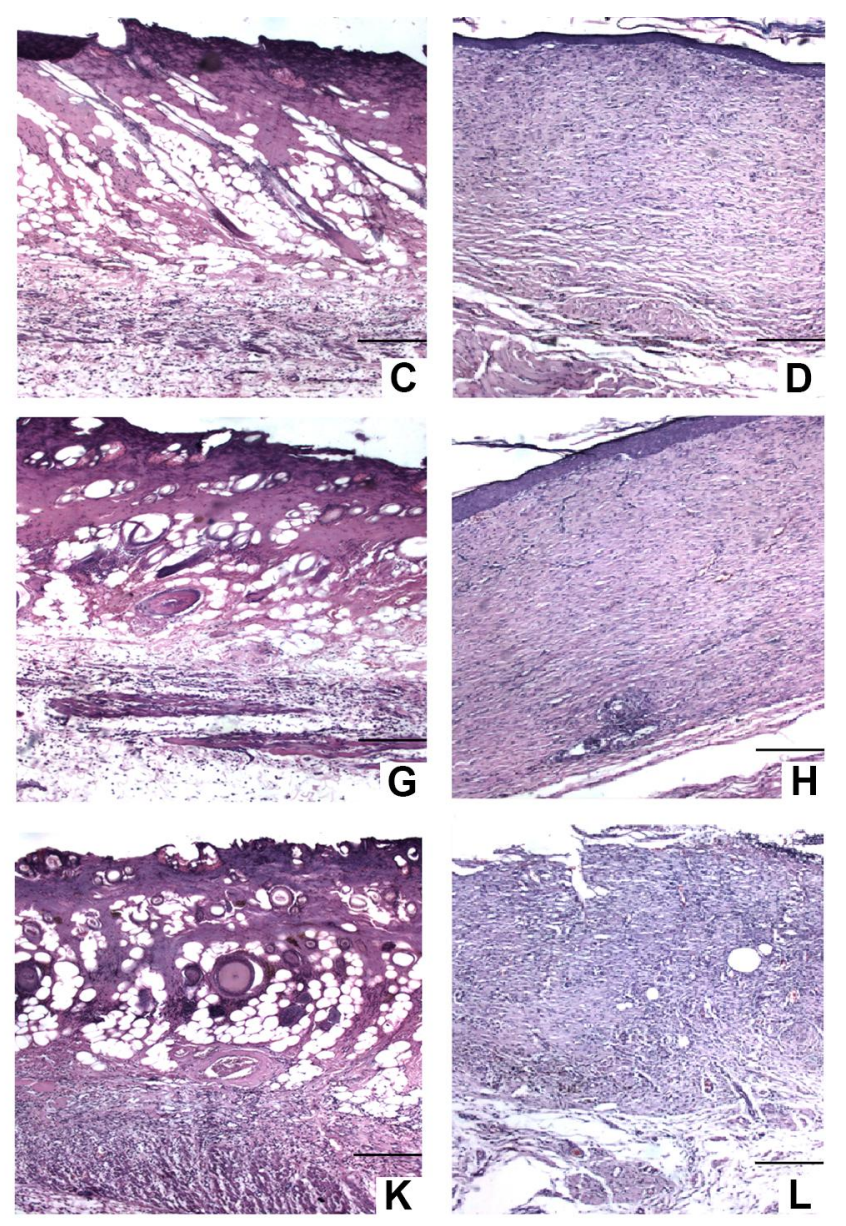
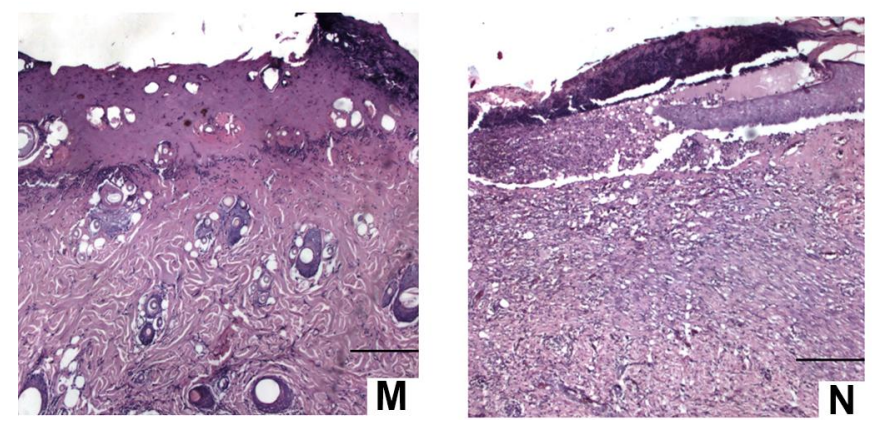

Figure 8 Histological sections of the burns of all groups (100x, bar $100 \mu \mathrm{m})$, allowing comparison of the healing achieved by all groups 30 days after the burn and treatment. RMG-LZ with cells on days 5 (A) and 30 (B), RMG-LZ without cells on days 5 (C) and 30 (D), RMGT-LZ with cells on days 5 (E) and 30 (F), RMGT-LZ without cells on days $5(\mathbf{G})$ and $30(\mathbf{H}), M C$ with cells on days $5(\mathbf{I})$ and $30(\mathbf{J})$, MC without cells on days $5(\mathbf{K})$ and $30(\mathbf{L})$, control on days $5(\mathbf{M})$ and $30(\mathbf{N})$.

Abbreviations: MSCs, mesenchymal stem cells; MC, cellulose membrane; RMG-LZ, reconstituted MC with $10 \%$ gellan gum and $10 \%$ lysozyme; RMGT-LZ, reconstituted MC with $10 \%$ tamarind xyloglucan plus gellan gum I:I and I0\% lysozyme.

proliferation rate achieved by RMGT-LZ and RMG-LZ. Some factors can explain this situation. First, the effect on charged surfaces by inclusion of gellan gum and lysozyme (observed in RMG-LZ and RMGT-LZ), and second, the morphology of the membranes after reconstitution of bacterial cellulose with additives by the casting process.

The first condition observed by the contact-angle results, showed that the inclusion of gellan gum, xyloglucan, and lysozyme made RMG-LZ and RMGTLZ surfaces more hydrophobic than MC and RM. As such, modulating surfaces with bioactive functional groups can modify the affinity of MSCs to explore this substrate as wound dressing. In accordance with this observation, previous studies have indicated that cell adhesion is more effective on moderately wettable surfaces. This probably occurs because moderately wettable polymers show an 
Table I Density of types I and III Collagen in the Collagen Area of the Scar

\begin{tabular}{|c|c|c|c|c|}
\hline & \multicolumn{4}{|c|}{ Collagen Density (\%) } \\
\hline & \multicolumn{2}{|l|}{5 Days } & \multicolumn{2}{|l|}{30 Days } \\
\hline & Type III Collagen & Type I Collagen & Type III Collagen & Type I Collagen \\
\hline RMG-LZ with MSCs & 80 & 20 & 7 & 92 \\
\hline RMG-LZ without MSCs & 79 & 21 & 6 & 94 \\
\hline RMGT-LZ with MSCs & 81 & 19 & 4 & 95 \\
\hline RMGT-LZ without MSCs & 82 & 18 & 8 & 91 \\
\hline$M C$ with MSCs & 79 & 20 & 4 & 97 \\
\hline MC without MSCs & 80 & 19 & 5 & 94 \\
\hline Control & 82 & 18 & 15 & 85 \\
\hline
\end{tabular}

Abbreviations: MSCs, mesenchymal stem cells; MC, commercial cellulose membrane; RMG-LZ, reconstituted cellulose membrane with $10 \%$ gellan gum and $10 \%$ lysozyme; RMGT-LZ, reconstituted cellulose membrane with 10\% tamarind xyloglucan plus gellan gum I:I and 10\% lysozyme.

exchange of surface-bound proteins for cell-secreted proteins, permitting the cells to produce and deposit their own adhering and spreading proteins. In addition, the authors observed that the interaction of the cell with the surface was reversible. ${ }^{42}$ Such an observation is interesting, because it allows the migration of MSCs from the membrane to the wound, confirmed by the immunocytochemistry results and migration assays, in which MSCs seeded on MC, RMG-LZ, and RMGT-LZ were able to migrate toward the bottom compartment of the culture well and kept expanding, maintaining their viability and metabolic activity.

The second condition regarding MSC adhesion and proliferation can be explained by the results of contactangle hysteresis. The increase in hysteresis of $\mathrm{MC}$ to RMG-LZ and RMGT-LZ indicated that the membrane surfaces with additives were rougher than the $M C$ and RM. RMGT-LZ contact-angle hysteresis was significantly higher than the RMG-LZ, indicating a rougher surface. This result is consistent with the cell-proliferation rate,
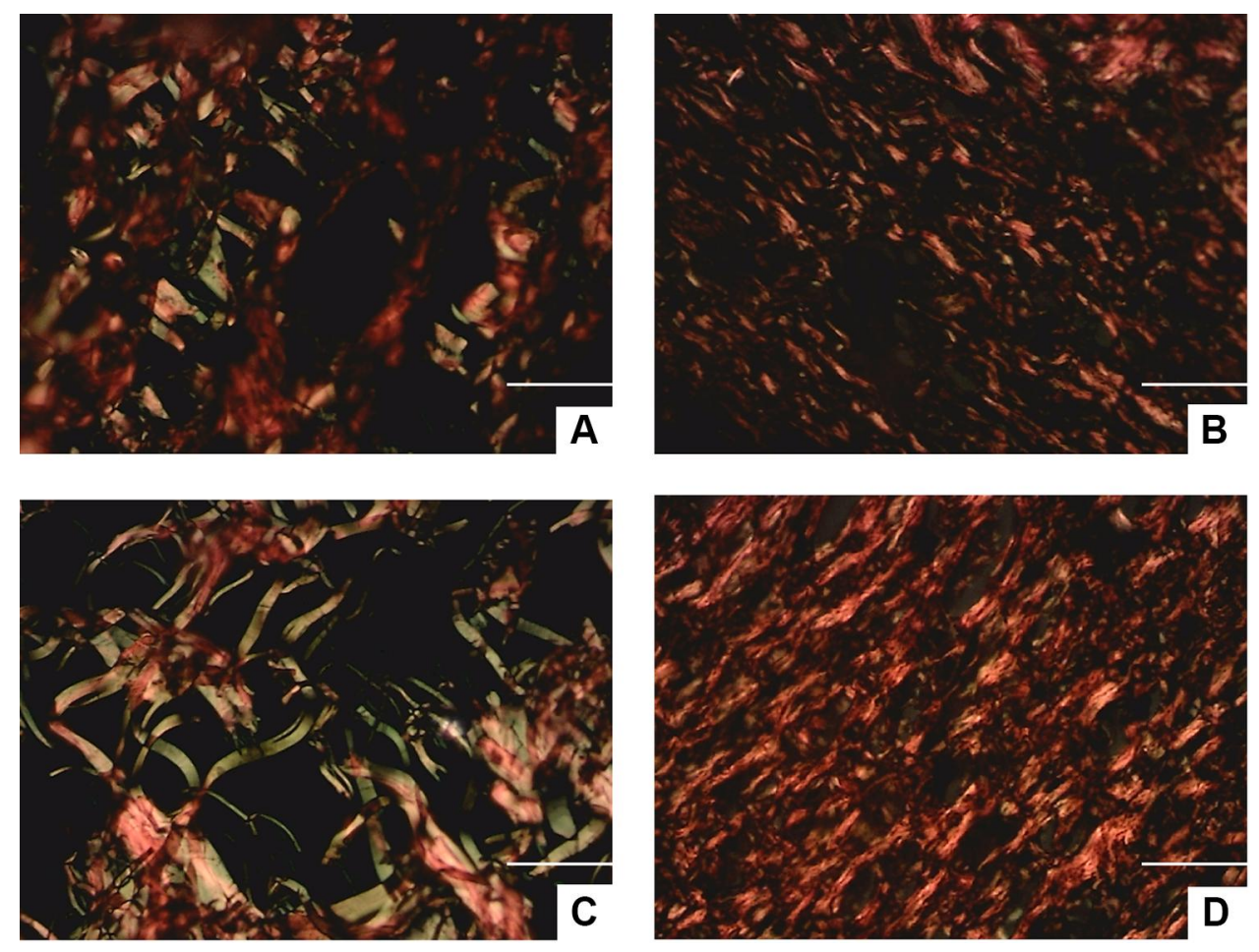

Figure 9 Microscopy of the collagen areas $(400 \times$, bar $50 \mu \mathrm{m})$ of the control group on days 5 (A) and 30 (B) and of MC with cells on days 5 (C) and 30 (D). Abbreviations: MC, cellulose membrane. 


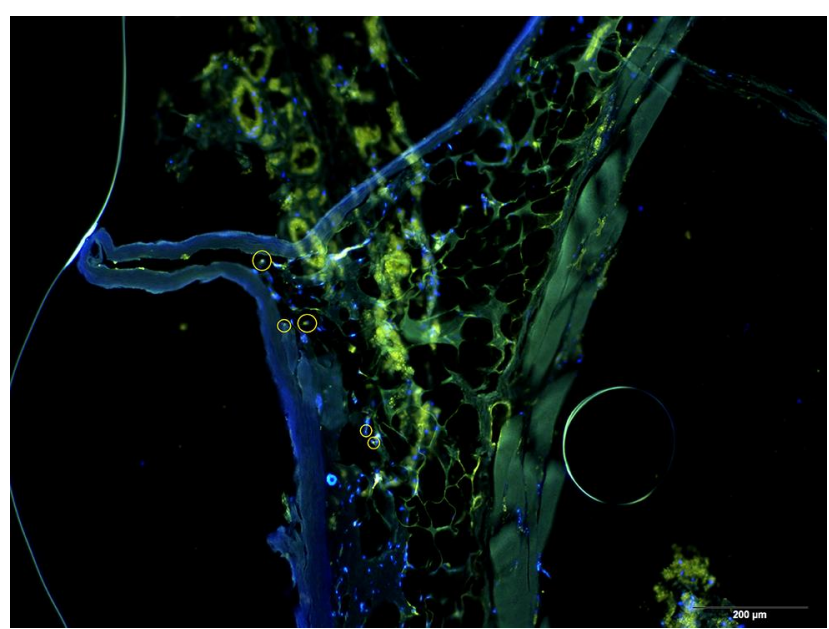

Figure 10 Microscopy of the injured area after 15 days of healing, showing MSCs that have migrated from RMGT-LZ to the wound. These MSCs express BrdU (green fluorescence) and have the nuclei marked by DAPI (blue fluorescence). 100x. Yellow circles indicate these cells.

Abbreviations: BrdU, bromodeoxyuridine; MSCs, mesenchymal stem cells; RMGT-LZ, reconstituted cellulose membrane with $10 \%$ tamarind xyloglucan plus gellan gum I:I and 10\% lysozyme.

which was significantly higher in RMGT-LZ than RMG$\mathrm{LZ}$ and the controls (MC and RM). SEM revealed more rugged surfaces of RMGT-LZ and RMG-LZ, which facilitated cell adhesion and proliferation. A rough surface with appropriately sized grooves or pores allows the anchoring of biological components and surface-texture cell adhesion. ${ }^{43}$

This characteristic can be related to the size of the fibers and the way they are arranged. On SEM, it was possible to observe the meshes forming, showing the difference among membranes-fiber sizes and arrangement, MSC, morphology, and their interaction with membrane surfaces. Smaller fibers improved cell-proliferation capacity. MC fibers were approximately $100 \mathrm{~nm}$ thick, typical for bacterial cellulose fibers displaying a microstructured mesh. However, with the inclusion of hydrocolloids, there was a decrease in pores, possibly due to the interaction with hydrocolloids. RMGT-LZ and RMG-LZ were formed by fibers $10-50 \mathrm{~nm}$ in thickness. This is consistent with a previous study that compared biofilms composed of differently sized nanofibers, and the thinner oned were more efficient for cell growth. ${ }^{44}$

Cellulose nanofibers have a large contact surface, which simulates the collagen-fibril network, showing biocompatibility, low cytotoxicity, and specific physicochemical characteristics, justifying its effective application in wound healing ${ }^{45}$ and tissue engineering associated with cell therapy. ${ }^{46,47}$ This allows a larger area of contact between membranes and MSCs and consequently to the injured surface.

As observed by SEM, MSC morphology was normal, similar to fibroblasts, presenting fusiform shape with digital expansions and standard colony formation ${ }^{48}$ for all the membranes. The cells expanded evenly, covering a wide area of RMGT-LZ, RMG-LZ, and MC surfaces, but cell growth was not so confluent on MC, consistent with the rates of adhesion and proliferation obtained. Nevertheless, a typical and effective cell-adhesion and -proliferation pattern was observed through cell morphology, indicating that all membranes were compatible with cellular development and potentially suitable as substrates for cell culture. This result corroborates other studies that have already described the cytocompatibility of cellulose membranes. ${ }^{49,50}$

The results showed that MSCs were able to differentiate on RMGT-LZ in adipogenic and osteogenic cells, which can be explained by the cross-linking density, porosity, and elasticity of the membrane, not interfering with the capacity of MSCs to differentiate into multiple cell types. ${ }^{51-53}$ It indicates that cellulose-gellan-xyloglucanlysozyme membranes are good support for cell differentiation.

For in vivo assays, all groups presented acute inflammatory response in 5 days, which was expected, since early infiltration of neutrophils and subsequent accumulation of macrophages and other immune cells in burned tissue characterizes the initial inflammatory response. ${ }^{54}$

In 70\% RMGT-LZ samples, with and without MSCs, polymorphonuclear leukocytes were frequently detected, forming dense and juxtaposed aggregates, with no areas free of infiltrates, in 5 days. This is an important indication of healing, since neutrophils and monocytes play key roles in the inflammatory phase of wound repair, as they secrete proinflammatory cytokines and growth factors. ${ }^{55}$

The RMGT-LZ trend was confirmed on day 30 by the evolution of acute inflammatory infiltrates in this group, which showed a reduction in infiltrate level - from accented and moderate to discreet and absent in 50\% and $40 \%$, respectively, of samples treated with MSCs - suggesting acceleration of the inflammatory process. It is likely that the inclusion of xyloglucan in RMGT-LZ promoted a load balance favorable to healing by stimulating cell growth and biological activity. It has been reported that xyloglucan has immunostimulating effects on monocytes, promotes macrophage activation, and increases nitric oxide production, modulating the inflammatory 
cascade. ${ }^{56}$ It was also capable of activating PLC $\gamma$, Src, and $\beta$-catenin and phosphorylating MAPK (STAT6 and STAT2), and PLC $\gamma$, CREB, cJun, eNOS, and p70S6. Most of these kinases and genes regulate cell survival, growth, and nutrition, but STAT2 is commonly involved in IFN-mediated immunoresponse. ${ }^{57}$

It is interesting to note that the $\mathrm{MC}$ with cells showed a significant evolution from days 5 to the 30 , whereby $80 \%$ of the samples that had had acute inflammatory infiltrates between accentuated and moderate evolved to discreet and only $20 \%$ remained moderate, pointing to the presence of the MSCs on MC (and RMGT-LZ) being decisive in faster resolution of acute inflammatory infiltrates over 30 days due to their immunomodulatory properties and paracrine anti-inflammatory activity. ${ }^{58,59}$

The presence of acute inflammatory infiltrate cells in the first 10 days and the beginning of chronic inflammation characteristics from this period have been reported. ${ }^{60}$ Herein, the presence of chronic inflammatory cells was discreet for most groups on day 5; however, in the $\mathrm{MC}$ group with MSCs, they were significantly identified, presenting fibroblasts and monomorphonuclear infiltrate cells with medium frequency, constituting dense aggregates, but keeping areas free of infiltration in $60 \%$ of samples. Once again, the immunomodulatory activity of MSCs interfered with this result.

The evolution of chronic inflammatory infiltrates was maintained in 30 days for the MC group with MSCs, presenting reduction in infiltrate levels from moderate to discreet in $70 \%$ of samples, showing the efficiency of this treatment.

RMGT-LZ with and without MSCs showed an interesting evolution in chronic inflammatory infiltrates, since $70 \%$ and $60 \%$ of their samples had no increase in inflammatory infiltrates in 30 days, remaining discreet. Resolution of the inflammatory process in the acute phase may have been influenced by the anti-inflammatory properties of xyloglucan, which has activity in mast-cell degranulation, interferes in the activity of such mediators as histamine and $\mathrm{PGE}_{2}$, and can decrease proinflammatory cytokine IL1 $\beta$ and IL6 release. ${ }^{61,62}$

Inflammatory response results for the groups treated with the dressings showed better performance than the control group, especially when seeded with MSCs. This occurred because cellulose membranes promote a moist environment conducive to healing, allowing gas exchange, avoiding infections through preventing the passage of microorganisms, stimulating the granulation process, and reducing pain. ${ }^{63,64}$
These benefits are enhanced by MSCs' anti-inflammatory and immunosuppressive effects, producing inhibitory factors such as as iNOS, indoleamine 2,3-dioxygenase, PGE2, TSG6, TGF $\beta$, HO1, MIG, ${ }^{65}$ reducing chemokine productio and thus decreasing the recruitment of peripheral leukocytes, ${ }^{59}$ with MSCs shifting from the production of proinflammatory to anti-inflammatory cytokines at the site of injury and suppressing lymphocyte alloreactivity. ${ }^{66}$

On evaluation of vascular proliferation on day 5 , the RMG-LZ groups obtained more pronounced results than the others, suggesting that the biofilm played an important role in these data. Gellan-gum incorporation was different between these groups. Gellan gum has no antigenic effects and does not directly stimulate the formation of new vessels; ${ }^{67}$ however, it has a positive effect on fibroblast adhesion and proliferation. ${ }^{68,69}$ Cells have a negative charge on the extracellular matrix and appear to have a greater preference for apolar and hydrophobic surfaces, so RMG-LZ possibly stimulated fibroblast growth at the burn site. Fibroblasts play a fundamental role in the angiogenesis process, secreting growth factors and producing matrix proteins that act in regulating the emergence of endothelial cells, stimulating the formation of lumenized tubular structures and the expansion of capillary networks. ${ }^{70}$ In a previous study, gellan-gum dressings were able to accelerate the healing process, promoting early overall revascularization and ensuring nourishment of neoformed tissue. ${ }^{16}$ In seeded membranes, MSC activity should be considered, reducing the amount of inflammatory infiltrates on lesion surfaces and promoting formation of new blood vessels and granulation tissue. ${ }^{71}$ MSCs are incorporated into capillary walls, expressing an endothelial phenotype and enhancing local vasculature, ${ }^{72}$ then by either direct differentiation or production and secretion of multiple paracrine proangiogenic factors, improve angiogenesis. ${ }^{73,74}$

RMGT-LZ groups with and without MSCs were the most efficient in cell-proliferation and in vivo assays. Results showed stimulation of burned-area epithelialization, presenting complete epithelialization in $90 \%$ of samples analyzed on the day 30. This indicates that the incorporation of tamarind xyloglucan in cellulose membrane used in this group influenced lesion epithelialization. The use of this biomaterial coverage alone is able to accelerate this process, involving the induction of reparative anti-inflammatory IL10 and M2-like macrophages, as well as the reduction of inflammatory cytokine TNF $\alpha$ and 
M1-like macrophages at the late inflammatory phase of burn-wound healing. ${ }^{75}$

The MC group seeded with MSCs obtained total epithelialization in $80 \%$ of samples, indicating that MSC presence also influenced accelerated epithelialization. This is explained by the migration capacity of MSCs from the curative membrane to underlying tissue comprised of neoepiderm and neoderma of the injured area, promoting higher density of blood vessels and acceleration of reepithelialization and keratinization. ${ }^{76}$ In addition, as the membrane is kept until the end of healing process without a need for exchange, the reepithelized area remains intact, accelerating tissue repair. ${ }^{77}$

There is an intimate relationship between epithelialization, collagen deposition, and fibroblast proliferation. This process is fundamental for burned-area recovery. During healing dynamics, collagen synthesis begins on day 3, peaks at 3-6 weeks, then undergoes remodeling. Type III collagen is initially synthesized and deposited, being gradually replaced by type I collagen as maturation of scar tissue occurs, ${ }^{78}$ which is shown in the microscopy of the collagen areas.

The density of type I and type III collagen was statistically equal for all groups in 5 days, but in 30 days all the treatment groups obtained better performance in the deposition of type III collagen, indicating better evolution of the healing process in the presence of the dressing. This result was more pronounced for MC with MSCs and also more efficient in deposition of type I collagen than the control group, indicating greater scar maturation in the presence of MSCs. This can be explained by MSCs stimulating dermal fibroblast migration and induce type I collagen secretion, accelerating granulation-tissue formation and increasing collagen deposition by direct mechanisms, such as differentiation in myofibroblasts and paracrine effects, such as growth-factor production, promoting proliferation and activity of fibroblasts. ${ }^{79,80}$ Fibroblasts are the main cells found in granulation tissue, and they secrete type III collagen and elastin, which together with type I collagen are important components of the extracellular matrix, so they play a key role in the healing process. ${ }^{81,82}$ In addition, the environment promoted by the dressing is favorable to healing.

By comparing the microscopic images of days 5 and 30 , resolution of the healing process is evident. The high compaction of collagen fibers in the dermis and color change inthe tissue (giving the cells a basophilic characteristic) had given rise to tissue with repaired epidermis, fibroblast accumulation, and neovascularization Inflammatory cells constituted of dense and juxtaposed aggregates begin to allow the visualization of free areas, with isolated inflammatory cells, exhibiting a few (or none) macrophages, lymphocytes, and plasma cells. ${ }^{83}$

All groups samples seeded with MSCs had a significant reduction in wound area (about 97\%) compared to the control group (about $88 \%$ ), which was treated only with gauze cover on the burn, reflecting a difference of $10 \%$. MSCs effectively improve the healing process by promoting angiogenesis and vascularization, modulating immunoresponse, and inducing epithelialization in the injured area. ${ }^{84}$ Myofibroblasts, mesenchymal cells exhibiting hybrid phenotype, with fibroblast and smooth musclecell characteristics that present high expression of $\alpha$-actin isoforms, may have stimulated the process of reduction in burned areas by contraction capacity, using the smooth muscle actin-myosin complex, which can accelerate healing by contracting the edges of the lesion. ${ }^{85}$

Therefore, the interface between wound and dressing provides a favorable environment for epithelial cells and keratinocyte migration, restoring skin integrity. The presence of MSCs on membranes assisted dermal proliferation of fibroblasts, significantly accelerating reduction of the injured area and avoiding hypertrophic scar formation. The use of scaffolding materials and MSCs resulted in functional healing, less deformity, effective vascularization, and more aesthetic outcomes for skin wounds. ${ }^{86}$

A common feature of RMG-LZ and RMGT-LZ, besides the nanostructured cellulose mesh, was the incorporation of lysozyme, which is a natural enzyme with strong antimicrobial activity against a broad spectrum of Gram-positive bacteria, some Gram-negative bacteria, and fungi. ${ }^{87}$ Bacterial cellulose nanofibers form an ultrafine and porous network architecture that facilitates the incorporation of lysozyme and its stability maintenance. ${ }^{88}$ Then, lysozyme activity may contribute to the maintenance of a microenvironment free of contamination and consequent acceleration of the healing process.

Immunocytochemical results proved that MSCs that migrated from the RMGT-LZ dressing to the burned tissue proliferated and provided therapeutic support, contributing to the healing process in a shorter period. Presumably, MSCs secreted a dynamic assortment of bioactive cytokines, trophic factors, and anti-inflammatory molecules, ${ }^{89}$ which backs their activity in the healing process. 
According to this study's results, the groups that obtained the best results in cell in vitro assays also showed the best performances in vivo. Nanostructured cellulosegellan-xyloglucan-lysozyme dressings seeded with MSCs improved several steps of the healing process and represent a promising alternative in treatment of burn injuries.

\section{Conclusion}

This study indicates the potential of exploring bacterial cellulose membranes blended with gellan gum, tamarind xyloglucan, and lysozyme as wound dressing. The inclusion of these additives on the celluloe matrix modified the hydrophilicity and modulated the surface of the membranes with the presence of bioactive functional groups, also resulting in different affinity of MSCs with biocurative effects. In addition, RMG-LZ and RMGT-LZ obtained the best results in vitro and in vivo. MSCs positively interfered in the healing process of the burns. The membranes seeded with MSCs improved the healing process, reduced acute/chronic inflammatory infiltrates, accelerated resolution of the inflammatory process, increased vascular proliferation, and stimulated epithelialization and a higher rate of collagen deposition, reducing the wound area in less time, and collagen deposition.

Cell therapy associated with nanostructured cellulosegellan-xyloglucan-lysozyme dressings was an efficient treatment in the regeneration of deep second-degree burns.

\section{Acknowledgments}

We thank Coordination for the Improvement of Higher Education Personnel Brazil (CAPES), Finance Code 001, and CNPq (process, 306245/2014-0) for financial support and Membracel for commercial cellulose-membrane donation.

\section{Disclosure}

The authors report no conflicts of interest in this work.

\section{References}

1. WHO. A WHO Plan for Burn Prevention and Care, WHO Press. Geneva, Switzerland: World Health Organization; 2008.

2. Serrano C, Boloix-Tortosa R, Gómez-Cía T, Acha B. Features identification for automatic burn classification. Burns. 2015;41(8):18831890. doi:10.1016/j.burns.2015.05.011

3. Wang Y, Beekman J, Hewet J, et al. Burn injury: challenges and advances in burn wound healing, infection, pain and scarring. $A d v$ Drug Deliv Rev. 2018;123:3-17. doi:10.1016/j.addr.2017.09.018

4. Brassolatti P, Kido HW, Bossini PS. Bacterial cellulose membrane used as biological dressings on third-degree burns in rats. Biomed Mater Eng. 2017;29(1):29-42. doi:10.3233/BME-171710
5. Mandelbaum SH, Santis EP. Healing: current concepts and ancillary resources - Part I. Br Ann Dermatol. 2003;78(4):393-410.

6. Pitanguy I, Salgado F, Maracajá PF. Utilização de película de celulose $\left(\right.$ Biofill ${ }^{\circledR}$ ) como curativo biologic. Rev Bras Cir. 1988;78 (5):317-326.

7. Chang WS, Chen HH. Physical properties of bacterial cellulose composites for wound dressings. Food Hydrocoll. 2016;53:75-83.

8. Lucyszyn N, Ono L, Lubambo AF, et al. Physicochemical and in vitro biocompatibility of films combining reconstituted bacterial cellulose with arabinogalactan and xyloglucan. Carbohydr Polym. 2016;151:889-898.

9. Czaja WK, Young JD, Kawecki M, et al. The Future Prospects of microbial cellulose in biomedical Applications. Biomacromolecules. 2007;8(1):1-12.

10. Silva FP, Alencar IR. Systematic review of the use of biomembranes in wounds and burns. Brochure of Culture and Science. 2016;15 (2):19-28.

11. Yudanova TN, Reshetov I. Modern wound dressings: manufacturing and properties. Pharm Chem J. 2006;40(2):85-92. doi:10.1007/ s11094-006-0065-z

12. John MJ, Thomas S. Biofibres and biocomposites. Carbohyd Polym. 2008;71(3):343-364. doi:10.1016/j.carbpol.2007.05.040

13. Harnett EM, Alderman J, Wood T. The surface energy of various biomaterials coated with adhesion molecules used in cell culture. Colloids Surf B Biointerfaces. 2007;55(1):90-97. doi:10.1016/j. colsurfb.2006.11.021

14. Bauer S, Schmuki P, Mark KVD, et al. Engineering biocompatible implant surfaces: part I: materials and surfaces. Prog Mater Sci. 2013;58(3):261-326. doi:10.1016/j.pmatsci.2012.09.001

15. Souza CF, Lucyszyn N, Woehl M, et al. Property evaluations of drycast reconstituted bacterial cellulose/tamarind xyloglucan biocomposites. Carbohydr Polym. 2013;93(1):144-153. doi:10.1016/j.carbpol. 2012.04.062

16. Cerqueira MT, Silva LP, Santos TC, et al. Human skin cell fractions fail to self-organize within a gellan gum/hyaluronic acid matrix but positively influence early wound healing. Tissue Eng Part A. 2014;20 (9-10):1369-1378. doi:10.1089/ten.tea.2013.0460

17. Muthukumar T, Song JE, Khang G. Biological role of gellan gum in improving scaffold drug delivery, cell adhesion properties for tissue engineering applications. Molecules. 2019;24(24):4514. doi:10.3390/ molecules 24244514

18. Gong Y, Wang C, Lai RC, et al. An improved injectable polysaccharide hydrogel: modified gellan gum for long-term cartilage regeneration in vitro. J Mater Chem. 2009;19(14):1968-1977. doi:10.1039/ b818090c

19. Osmalek T, Froelich A, Tasarek S. Application of gellan gum in pharmacy and medicine. Int $J$ Pharm. 2014;466(1-2):328-340. doi:10.1016/j.ijpharm.2014.03.038

20. Gurjão KCO, Bruno RLA, Almeida FAC, et al. Development fruits and seeds of tamarind. Brazilian Journal of Fruticulture. 2006;28 (3):351-354.

21. Nayak AK, Pal D, Santra K. Screening of polysaccharides from tamarind, fenugreek and jackfruit seeds as pharmaceutical excipients. Int $J$ Biol Macromol. 2015;79:756-760. doi:10.1016/j.ijbiomac.2015.05.018

22. Drago H, Marín GH, Sturla F, et al. The next generation of burns treatment: intelligent films and matrix, controlled enzymatic debridement, and adult stem cells. Transplant Proc. 2010;42(1):345-349. doi:10.1016/j.transproceed.2009.11.031

23. Maranda EL, Rodriguez-Menocal L, Badiavas EV. Role of mesenchymal stem cells in dermal repair in burns and diabetic wounds. Curr Stem Cell Res Ther. 2017;12(1):61-70. doi:10.2174/1574888X116 66160714115926

24. Fierabracci A, Del Fattore A, Luciano R, et al. Recent advances in mesenchymal stem cell immunomodulation: the role of microvesicles. Cell Transplant. 2015;24(2):133-149. doi:10.3727/09636891 $3 \times 675728$ 
25. Meyerrose TE, de Ugarte DA, Hofling AA, et al. In vivo distribution of human adipose-derived mesenchymal stem cells in novel xenotransplantation models. Stem Cells. 2007;25(1):220-227. doi:10.16 34/stemcells.2006-0243

26. Semenov OV, Koestenbauer S, Riegel M, et al. Multipotent mesenchymal stem cells from human placenta: critical parameters for isolation and maintenance of stemness after isolation. Am J Obstet Gynecol. 2010;202(193):1-13. doi:10.1016/j.ajog.2009.10.869

27. Castro-Manrreza ME, Montesinos JJ. Immunoregulation by mesenchymal stem cells: biological aspects and clinical applications, J. Immunol Res. 2015;394917.

28. Mortada I, Mortada R. Epigenetic changes in mesenchymal stem cells differentiation. Eur J Med Genet. 2017;S1769(17):30444-30445.

29. Shotorbani BB, Alizadeh E, Salehi R, et al. Adhesion of mesenchymal stem cells to biomimetic polymers: a review. Mater Sci Eng C Mater Biol Appl. 2017;71:1192-1200. doi:10.1016/j.msec.2016.10.013

30. Chandra V, Swetha G, Phdnis S, et al. Generation of pancreatic hormone-expressing islet-like cell aggregates from murine adipose tissue-derived stem cells. Stem Cells. 2009;27(8):1941-1953. doi: $10.1002 /$ stem. 117

31. Irioda AC, Zocche L, Souza CMCO, et al. Pap Test as the first step in screening genetic stability in cell-based therapy. J Stem Cell Res Ther. 2011;1(03):106. doi:10.4172/2157-7633.1000106

32. Zuk PA, Zhu M, Mizuno H, et al. Multilineage cells from human adipose tissue: implications for cell-based therapies. Tissue Eng 2001;7:211e28. doi:10.1089/107632701300062859

33. Noel D, Caton D, Roche S, et al. Cell specific differences between human adipose-derived and mesenchymal stromal cell despite similar differentiation potentials. Exp Cell Res. 2008;314:1575-1584. doi:10. 1016/j.yexcr.2007.12.022

34. Souza CMCO, Mesquita LAF, Souza D, et al. Regeneration of skin tissue promoted by mesenchymal stem cells seeded in nanostructured membrane. Transplant Proc. 2014;46(6):1882-1886. doi:10.1016/j. transproceed.2014.05.066

35. Mogharbel BF, Francisco JC, Irioda AC, et al. Fluorescence properties of curcumin-loaded nanoparticles for cell tracking. Int $J$ Nanomedicine. 2018;13:5823-5836. doi:10.2147/IJN.S171099

36. Kilkenny C, Browne WJ, Cuthill IC, et al. Altman, Improving bioscience research reporting: the arrive guidelines for reporting animal research. Animals. 2013;4(1):35-44. doi:10.3390/ani4010035

37. Biondo-Simões MLP, Spelling NW, Ioshii SI, et al. The influence of nicotine on collagen density in cutaneous scars in rats. $\mathrm{J} \mathrm{Br}$ Coll Surg. 2009;36(5):425-430.

38. Javazon EH, Beggs KJ, Flake AW. Mesenchymal stem cells: paradoxes of passaging. Exp Hematol. 2004;32(5):414-425. doi:10.1016/ j.exphem.2004.02.004

39. Zhang HS, Fang JP, Su HB, Yang M. Culture in vitro and lentivirus transfection of rat mesenchymal stem cells. J Exp Hematol. 2011;19 (6):1472-1476.

40. Faucheux N, Schweiss R, Lützow K, et al. Self-assembled monolayers with different terminating groups as model substrates for cell adhesion studies. Biomaterials. 2004;25(14):2721-2730. doi:10.10 16/j.biomaterials.2003.09.069

41. Zhao C, Tan A, Pastorin G, Ho HK. Nanomaterial scaffolds for stem cell proliferation and differentiation in tissue engineering. Biotech Adv. 2017;29(1):654-668. doi:10.1016/j.biotechadv. 2012.08.001

42. Van-Wachem PB, Beugeling T, Feijen J, et al. Interaction of cultured human endothelial cells with polymeric surfaces of different wettabilities. Biomaterials. 1985;6(6):403-408.

43. Lee C, Kim SH, Jang JH, Lee SY. Enhanced cell adhesion on a nanoembossed, sticky surface prepared by the printing of a dopa-bolaamphiphile assembly ink. Sci Rep. 2017;7:13797.

44. Qu J, Zhou D, Xu X, et al. Optimization of electrospun TSF nanofiber alignment and diameter to promote growth and migration of mesenchymal stem cells. Appl Surf Sci. 2012;261:320-326.
45. Alexandrescu L, Syverud K, Gatti A, Chinga-Carrasco G. Cytotoxicity tests of cellulose nanofibril-based structures. Cellulose. 2013;20:1765-1775.

46. Naseri N, Poirier JM, Girandon L, et al. 3-Dimensional porous nanocomposite scaffolds based on cellulose nanofibers for cartilage tissue engineering: tailoring of porosity and mechanical performance. RSC Adv. 2016;6:5999-6007.

47. Chang HT, Heuer RA, Oleksijew AM, et al. An engineered threedimensional stem cell niche in the inner ear by applying a nanofibrillar cellulose hydrogel with a sustained-release neurotrophic factor delivery system. Acta Biomater. 2020;108:111-127.

48. Gaiba S, França LP, França JP, Ferreira LM. Characterization of human adipose-derived stem cells. Acta Cir Bras. 2012;27(7):471476.

49. Beladi F, Saber-Samandari S. Cellular compatibility of nanocomposite scaffolds based on hydroxyapatite entrapped in cellulose network for bone repair. Mater Sci Eng C Mater Biol Appl. 2017;75:385-392.

50. Gorgieva S, Girandon L, Kokol V. Mineralization potential of cellulosenanofibrils reinforced gelatine scaffolds for promoted calcium deposition by mesenchymal stem cells. Mater Sci Eng. 2017;73:478-489.

51. Shen H, Ma Y, Liu X, et al. Directed osteogenic differentiation of mesenchymal stem cell in three-dimensional biodegradable methylcellulose-based scaffolds. Coll Surf B. 2015;1(135):332-338.

52. Cochis A, Grad S, Stoddart MJ, et al. Bioreactor mechanically guided 3D mesenchymal stem cell chondrogenesis using a biocompatible novel thermo-reversible methylcellulose-based hydrogel. Sci Rep. 2017;7:45018.

53. Kooshki H, Ghollasi M, Halabian R, Kazemi NM. Osteogenic differentiation of preconditioned bone marrow mesenchymal stem cells with lipopolysaccharide on modified poly-l-lactic-acid nanofibers. $J$ Cell Physiol. 2019;234(5):5343-5353.

54. Li G, Feng X, Wang $\mathrm{S}$. Effects of $\mathrm{Cu} / \mathrm{Zn}$ superoxide dismutase on strain injury-induced oxidative damage to skeletal muscle in rats. Physiol Res. 2005;54:193-199.

55. Silveira PC, Ferreira KB, Rocha FR, et al. Effect of Low-Power Laser (LPL) and Light-Emitting Diode (LED) on Inflammatory Response in Burn Wound Healing. Inflammation. 2016;39(4):1395-1404.

56. Mmt R, Noleto GR, Bento JF, et al. Effect of storage xyloglucans on peritoneal macrophages. Phytochemistry. 2008;69:464-472.

57. Nie W, Deters AM. Tamarind seed xyloglucans promote proliferation and migration of human skin cells through internalization via stimulation of proproliferative signal transduction pathway. Dermatol Res Pract. 2013;2013:359756.

58. Caplan AI. Adult mesenchymal stem cells for tissue engineering versus regenerative medicine. J Cell Physiol. 2007;213:341-347.

59. Zhang R, Liu Y, Yan K, et al. Anti-inflammatory and immunomodulatory mechanisms of mesenchymal stem cell transplantation in experimental traumatic brain injury. $J$ Neuroinflammation. 2013;10:106.

60. Orgaes FAFS, Lyra MC, Jr OF R, et al. Histopathologic study of the use of topical heparin in scalded rats burns. $J$ Br Soc Plastic Surg. 2007;22(1):39-44.

61. Cunha PLR, Vieira IGP, Arriga AMC, et al. Isolation and characterization of galactomannan from Dimorphandra gardneriana Tul. Seeds Potential Guar Gum Substitute Food Hydrocoll. 2009;23(3):880885.

62. Periasamy S, Lin $\mathrm{CH}$, Nagarajan B, et al. Mucoadhesive role of tamarind xyloglucan on inflammation attenuates ulcerative colitis. $J$ Funct Foods. 2018;47:1-10.

63. Shores JT, Gabriel A, Gupta S. Skin substitutes and alternatives: a review. Adv Skin Wound Care. 2007;20:493-508.

64. Piatkowski A, Drummer N, Andriessen A, et al. Randomized controlled single center study comparing a polyhexanide containing biocellulose dressing with silver sulfadiazine cream in partial-thickness dermal burns. Burns. 2011;37(5):800-804. 
65. Shi Y, Su J, Roberts AI, Shou P, Rabson AB, Ren G. How mesenchymal stem cells interact with tissue immune responses. Trends Immunol. 2012;33:136-143.

66. Le-Blanc K, Ringdén OJ. Immunomodulation by mesenchymal stem cells and clinical experience. Intern Med. 2007;262(5):509-525.

67. Silva-Correia J, Miranda-Gonçalves V, Salgado AJ, et al. Angiogenic potential of gellan-gum-based hydrogels for application in nucleus pulposus regeneration: in vivo study. Tissue Eng Part A. 2012;18(1112):1203-1212.

68. Ismail NA, Amin KA, Majid FAA, Razali MH. Gellan gum incorporating titanium dioxide nanoparticles biofilm as wound dressing: physicochemical, mechanical, antibacterial properties and wound healing studies. Mater Sci Eng. 2019;103:109770.

69. Xu Z, Li Z, Jiang S, Bratlie KM. Chemically modified gellan gum hydrogels with tunable properties for use as tissue engineering scaffolds. ACS Omega. 2018;3(6):6998-7007.

70. Ramphul H, Gimié F. Sugar-cane bagasse cellulose-based scaffolds promote multi-cellular interactions, angiogenesis and reduce inflammation for skin tissue regeneration. Int J Biol Macromol. 2020;157 (15):296-310.

71. Rasulov MF, Vasilenko VT, Zaidenov VA. Onishchenko. Cell transplantation inhibits inflammatory reaction and stimulates repair processes in burn wound. Cell Techn Biol Med. 2006;2(3):112-115.

72. Franck CL, Ribas-Filho JM, Senegaglia AC, Graf RM, Leite LMB. The complexity of burn healing and the possibility of adipose tissuederived stem cell therapy: review. Br J Burns. 2017;16(2):111-116.

73. Wang N, Chen C, Yang D, et al. Mesenchymal stem cells-derived extracellular vesicles, via miR-210, improve infarcted cardiac function by promotion of angiogenesis. Biochim Biophys Acta. 2017;1863 (8):2085-2092.

74. Kwon HM, Hur SM, Park KY, et al. Multiple paracrine factors secreted by mesenchymal stem cells contribute to angiogenesis. Vascul Pharmacol. 2014;63(1):19-28.

75. Alapure BV, Lu Y, He M, et al. Accelerate healing of severe burn wounds by mouse bone marrow mesenchymal stem cell-seeded biodegradable hydrogel scaffold synthesized from arginine-based poly (ester amide) and chitosan. Stem Cells Dev. 2018;27(23):1605-1620.

76. Liu P, Deng Z, Han Z, et al. Tissue - engineered skin containing mesenchymal stem cells improves burn wounds. Artif Organs. 2008;32(12):925-931.

77. Zajicek R, Matouskova E, Broz L, et al. New biological temporary skin cover Xe-Derma ${ }^{\circledR}$ in the treatment of superficial scald burns in children. Burns. 2011;37(2):333-337.
78. McDougall S, Dallon J, Sherrat J, Maini P. Fibroblast migration and collagen deposition during dermal wound healing: mathematical modeling and clinical implications. Philosophical Trans Royal Soc. 2006;364(1843):1385-1405.

79. Volk SW, Radu A, Zhang L, Liechty KW. Stromal progenitor cell therapy correscts the wound - healing defect in the ischemic rabbit ear model of chronic wound repair. Wound Repair Regeneration. 2007;15:736-747.

80. Chen L, et al. Conditioned medium from hypoxic bone marrowderived mesenchymal stem cells enhances wound healing in mice. PLoS One. 2014;9:e96161.

81. Liang X, Ding Y, Zhang Y, Tse HF, Lian Q. Paracrine mechanisms of mesenchymal stem cell-based therapy: current status and perspectives. Cell Transpl. 2014;23:1045-1059.

82. Ochiai H, Kishi K, Kubota Y. Transplanted mesenchymal stem cells are effective for skin regeneration in acute cutaneous wounds of pigs. Regenerative Therapy. 2017;7:8-16.

83. Guimarães PL, Silva EA, Bardella RA, Crisci AR. Evolução de queimaduras sob ação de diferentes agentes tópicos. Perspec Online. 2012;7(2):14-22.

84. Hassanshahi A, Hassanshahi M, Khabbazi S, et al. Adipose-derived stem cells for wound healing. J Cell Physiol. 2019;234(6):79037914.

85. Perez EG, Mlr P, Bonan P, et al. Tuberous sclerosis: evaluation of myofibroblasts in cutaneous angiofibromas - Case report. $\mathrm{Br}$ Ann Dermatol. 2010;85(1):84-88.

86. Samberg M, Stone R, Natesan S, et al. Platelet rich plasma hydrogels promote in vitro and in vivo angiogenic potential of adipose-derived stem cells. Acta Biomater. 2019;S1742(19):30059.

87. Dembczynski R, Bialas W, Regulski K, Jankowski T. Lysozyme extraction from hen egg white in an aqueous two-phase system composed of ethylene oxide-propylene oxide thermoseparating copolymer and potassium phosphate. Process Biochem. 2010;45(3):369374.

88. Bayazidi P, Almasi H, Asl AK. Immobilization of lysozyme on bacterial cellulose nanofibers: characteristics, antimicrobial activity and morphological properties. Int J Biol Macromol. 2018;107(Pt B):2544-2551.

89. Kimbrel EA, Kouris NA, Yavanian GJ, et al. Mesenchymal stem cell population derived from human pluripotent stem cells displays potent immunomodulatory and therapeutic properties. Stem Cells Dev. 2014;23(14):1611-1624.
International Journal of Nanomedicine

\section{Publish your work in this journal}

The International Journal of Nanomedicine is an international, peerreviewed journal focusing on the application of nanotechnology in diagnostics, therapeutics, and drug delivery systems throughout the biomedical field. This journal is indexed on PubMed Central, MedLine, CAS, SciSearch ${ }^{\mathbb{}}$, Current Contents ${ }^{\mathbb{R}} /$ Clinical Medicine, $^{-}$
Journal Citation Reports/Science Edition, EMBase, Scopus and the Elsevier Bibliographic databases. The manuscript management system is completely online and includes a very quick and fair peer-review system, which is all easy to use. Visit http://www.dovepress.com/ testimonials.php to read real quotes from published authors. 